\title{
Applications of a Spatially Variable Advection Correction Technique for Temporal Correction of Dual-Doppler Analyses of Tornadic Supercells
}

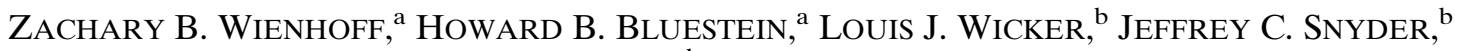 \\ Alan Shapiro, ${ }^{\mathrm{c}}$ Corey K. Potvin, ${ }^{\mathrm{d}} \mathrm{JAN}$ A B. Houser,${ }^{\mathrm{e}}$ AND Dylan W. ReiF ${ }^{\mathrm{a}}$ \\ ${ }^{\text {a }}$ School of Meteorology, University of Oklahoma, Norman, Oklahoma \\ ${ }^{\mathrm{b}}$ NOAA/OAR/National Severe Storms Laboratory, Norman, Oklahoma \\ ${ }^{\mathrm{c}}$ School of Meteorology, and Center for Analysis and Prediction of Storms, University of Oklahoma, Norman, Oklahoma \\ ${ }^{\mathrm{d}}$ School of Meteorology, and Cooperative Institute for Mesoscale Meteorological Studies, University of \\ Oklahoma, and NOAA/OAR/National Severe Storms Laboratory, Norman, Oklahoma \\ ${ }^{\mathrm{e}}$ Department of Geography, Ohio University, Athens, Ohio
}

(Manuscript received 28 November 2017, in final form 16 July 2018)

\begin{abstract}
In many instances, synchronization of Doppler radar data among multiple platforms for multiple-Doppler analysis is challenging. This study describes the production of dual-Doppler wind analyses from several case studies using data from a rapid-scanning, X-band, polarimetric, Doppler radar-the RaXPol radar-and data from nearby WSR-88Ds. Of particular interest is mitigating difficulties related to the drastic differences in scanning rates of the two radars. To account for differences in temporal resolution, a variational reflectivity tracking scheme [a spatially variable advection correction technique (SVAC)] has been employed to interpolate (in a Lagrangian sense) the coarser temporal resolution data (WSR-88D) to the times of the RaXPol volume scans. The RaXPol data and temporally interpolated WSR-88D data are then used to create quasi-rapid scan dual-Doppler analyses. This study focuses on the application of the SVAC technique to WSR-88D data to create dual-Doppler analyses of three tornadic supercells: the 19 May 2013 Edmond-Carney and Norman-Shawnee, Oklahoma, storms and the 24 May 2016 Dodge City, Kansas, storm. Results of the dual-Doppler analyses are briefly examined, including observations of the $Z_{\mathrm{DR}}$ columns as a proxy for updrafts. Potential improvements to this technique are also discussed.
\end{abstract}

\section{Introduction}

Dual-Doppler analysis of severe convective storms has been an important technique for furthering our understanding of tornadic thunderstorms, particularly from a network of S-band radars (10-cm wavelength) operated by the National Severe Storms Laboratory (NSSL) in central Oklahoma (e.g., Brown and Peace 1968; Brown et al. 1975; Ray et al. 1975; Ray 1976; Brandes 1977a, b; Eagleman and Lin 1977; Brandes 1978; Ray et al. 1981; Brandes 1984a, b; Dowell and Bluestein 1997). Although the NSSL S-band dual-Doppler network provided data for many dualDoppler studies, the coarse spatial resolution provided by the S-band radars (generally 3-5 times coarser gate spacing than mobile radars) and the inability to reposition the instruments led to the creation and implementation of some of the first mobile radar platforms. Mobile radars transmitting at W-band ( 3-mm wavelength; Bluestein

Corresponding author: Zachary B. Wienhoff, wienhoff@ou.edu and Pazmany 2000), X-band (3-cm wavelength; e.g., Wurman et al. 1997; Alexander and Wurman 2005; Bluestein et al. 2007; Palmer et al. 2009; Knupp et al. 2014), and C-band (5-cm wavelength; Biggerstaff et al. 2005) have been used to document tornadoes and supercells at higher resolution than is typically obtained using fixed-site S-band radars such as the Weather Surveillance Radar-1988 Dopplers (WSR-88Ds). The idea to utilize such mobile platforms for dual-Doppler analysis was first proposed by Bluestein et al. (1995) using 3-mm wavelength radars and implemented first at X-band using the Doppler on Wheels (Wurman et al. 1997; Alexander and Wurman 2005).

In the past 20 years, the increase in the number of mobile, ground-based radars has not only allowed severe weather researchers to obtain dual-Doppler analyses more easily, but has also increased observations of stormscale and smaller phenomena (e.g., supercells and tornadoes) at close range (e.g., Wurman et al. 2007a, b; Marquis et al. 2008; Wurman et al. 2010; Wakimoto et al. 2011; 
TABLE 1. List of RaXPol deployments on 19 May 2013.

\begin{tabular}{clll}
\hline \hline Deployment & \multicolumn{1}{c}{ Time } & \multicolumn{1}{c}{ Location } & Tornado observed \\
\hline 1.1 & $2016-2020$ UTC & North of Guthrie, OK & (None) \\
1.2 & $2040-2048$ UTC & North of Guthrie, OK & (None) \\
2 & $2145-2221$ UTC & 3 mi ENE of Wellston, OK & Edmond-Carney \\
3 & $2301-2321$ UTC & 4 mi NNW of Bethel Acres, OK & Norman-Shawnee \\
4 & $2327-2331$ UTC & 2 mi NW of Bethel Acres, OK & Norman-Shawnee \\
5 & $2341-0005$ UTC & 3 mi SW of Shawnee, OK & (None) \\
6 & $0119-0125$ UTC & Near Okemah, OK & \\
\hline
\end{tabular}

Atkins et al. 2012; Markowski et al. 2012a, b; Wakimoto et al. 2012; Tanamachi et al. 2012; Kosiba et al. 2013). One of the more recent additions to the mobile radar fleet in support of severe convection research is a mobile, rapidscanning, X-band, polarimetric Doppler radar (RaXPol; Pazmany et al. 2013), which combines polarimetric capabilities with rapid data collection using a mechanically scanning radar.

On multiple occasions, RaXPol has collected high temporal and spatial resolution data on a tornadic supercell storm at relatively close distance (e.g., $<40 \mathrm{~km}$ ) from a WSR-88D. In several cases, the RaXPol deployments were such that the cross-beam angles between the RaXPol and the WSR-88D were sufficient to allow reliable dual-Doppler wind syntheses. However, in all of these cases, major differences in the radars' sampling rates posed significant challenges in combining these datasets for dual-Doppler analysis. Without properly accounting for these temporal differences, dual-Doppler analyses based on data from a rapid scan mobile radar and a WSR-88D would likely offer minimal benefit.

The primary objective of this paper is to explore several methods for 3D dual-Doppler wind retrieval, including one in which WSR-88D data are temporally interpolated using a spatially variable advection correction technique (SVAC). Toward this end, each dualDoppler technique's performance will be assessed based on analysis of retrieved vertical vorticities within the supercell's mesocyclone, and by leveraging the location of the $Z_{\mathrm{DR}}$ column in the WSR-88D data as a proxy for the location of the supercell updraft, which will be compared to the obtained vertical velocities. While the majority of this study will focus on analyses of the 19 May 2013 Edmond-Carney, Oklahoma, tornadic supercell, we will also briefly discuss analyses of the 19 May 2013 Norman-Shawnee, Oklahoma, and the 24 May 2016 Dodge City, Kansas, supercell storms, which serve as additional test cases for this technique.

\section{Instrumentation and data}

Included in this study are datasets from three different radar platforms: the Oklahoma City and Dodge
CityWSR-88Ds (KTLX and KDDC, respectively), and the RaXPol mobile radar. The WSR-88D network consists of 160 polarimetric Doppler radars used by the National Weather Service for weather surveillance across the United States. These fixed-site radars have a maximum scanning rate of $30^{\circ} \mathrm{s}^{-1}$ in azimuth and in elevation, resulting in volume update times ranging from 4 to greater than $6 \mathrm{~min}$ depending on the chosen rescanning mode. ${ }^{1}$ The legacy radial spacing of the WSR-88D data is $1^{\circ}$; gate spacing is $250 \mathrm{~m}$ for radial velocity and spectrum width but $1 \mathrm{~km}$ for all other products. Recent upgrades to "super resolution" implement azimuthal oversampling and improved resolution for nonvelocity products; radial spacing is decreased to $0.5^{\circ}$ and range gate spacing of $250 \mathrm{~m}$ is used for all base products at the lowest levels (Torres and Curtis 2006).

$\mathrm{RaXPol}$ is a radar mounted on a truck (Pazmany et al. 2013). Maintained by the Advanced Radar Research Center (ARRC) at the University of Oklahoma, the RaXPol can mechanically scan at a rate of $180^{\circ} \mathrm{s}^{-1}$, offering more than 5 times the volumetric updates as compared to a WSR-88D. In addition, the mechanically scanning nature of RaXPol has the added benefits of dualpolarization and a beamwidth narrower than that of other mobile rapid-scanning radars, such as those with phasedarray antennas that are usually singly polarized and often suffer from wider beamwidths (e.g., Bluestein et al. 2010). $\mathrm{RaXPol}$ has been used to collect radar data in supercells and tornadoes (e.g., Snyder et al. 2013; Snyder and Bluestein 2014; Bluestein et al. 2015; Houser et al. 2015, 2016; Wakimoto et al. 2015, 2016) as well as nonprecipitating phenomena such as cold fronts and prefrontal wind shifts (e.g., Bluestein et al. 2017).

On 19 May 2013, the RaXPol deployed six times (Table 1), but only deployments 2 (D2), 3 (D3), and 5 (D5) are examined in this paper. Deployments 1 and

\footnotetext{
${ }^{1}$ WSR-88D rescanning modes include Supplemental Adaptive Intravolume Low-Level Scans (SAILS), Multiple Elevation Scan Option SAILS (MESO-SAILS), and Mid-Volume Rescan of Low-Level Elevations (MRLE). More information can be found at https://www.roc.noaa.gov/.
} 
TABLE 2. List of RaXPol deployments on 24 May 2016.

\begin{tabular}{cccc}
\hline \hline Deployment & Time & Location & Tornado observed \\
\hline 1 & $2314-2341$ UTC & 6 mi S of Dodge City, KS & $\sim 8$ tornadoes \\
2 & $2356-0007$ UTC & $2 \mathrm{mi} \mathrm{S}$ of Dodge City, KS & 1 multivortex tornado \\
3 & $0055-0117$ UTC & $1.5 \mathrm{mi}$ WSW Kinsley, KS & Anticyclone tornado \\
\hline
\end{tabular}

6 occurred before and after the occurrence of the tornadoes of interest, respectively, while during deployment 4 the Norman-Shawnee tornado was not situated in a location suitable for dual-Doppler analysis because the tornado was located along the dual-Doppler baseline. The 24 May 2016 dataset was collected during three deployments, but only a small subset of deployment 1 ( 2329-2334 UTC) is considered here (Table 2).

\section{Dual-Doppler methodology}

This section focuses on the four main steps used to produce dual-Doppler analyses: data quality control, spatial objective analysis, temporal correction for nonsimultaneous data collection, and the dual-Doppler wind synthesis.

\section{a. Radar data quality control}

In general, radar-data quality depends in large part on the number of samples collected within each volume (i.e., the dwell time and pulse repetition frequency) and on atmospheric motions within the volume. In the case of the RaXPol operating at its maximum rotation rate, the number of samples per volume is small enough to cause some data quality degradation. In addition, the atmospheric motions associated with tornadoes, such as the significant tornadoes examined in this paper, often are characterized by exceptionally high spectrum widths owing to turbulence and/or sharp gradients in velocities. The high (normalized) spectrum widths and debris within the tornado can reduce the probability that the true mean radial velocity is estimated properly. On the other hand, owing to the polarimetric capability of RaXPol, estimates of the mean velocity in a tornadic debris cloud, in which the horizontally and vertically polarized backscattered signals are not well correlated, can be improved (Snyder and Bluestein 2014). In any event, as a result of these issues and the sensitivity of the dual-Doppler analysis method to radial velocity errors, data quality control is extremely important to our analyses.

For each of these cases, data were edited using the National Center for Atmospheric Research's (NCAR) SOLO3 software (Bell et al. 2013). Velocity data were first thresholded on normalized coherent power (NCP) below 0.24 , a signal-quality index that utilizes both spectrum width and signal-to-noise ratio to remove lowquality data (e.g., Schroth et al. 1988). Ground clutter was subjectively removed from low levels, and the radial velocities were dealiased manually.

\section{b. Objective analysis}

Data from RaXPol and the nearby WSR-88D were mapped to a Cartesian grid using a two-pass Barnes's analysis (Barnes 1964) using Observation Processing and Wind Synthesis (OPAWS; Majcen et al. 2008) software. Objective analysis parameters were then chosen based on the coarser of the two radars' resolutions (generally from the WSR-88D) valid at the estimated center of the mesocyclone. Prior to each Barnes's analysis, the maximum distance of the mesocyclone from the radar location was measured, and the distance between successive azimuths (resulting in the coarsest resolution) was used throughout to calculate the proper gridding parameters.

The locations of the radars and the corresponding $30^{\circ}$ dual-Doppler lobes are provided in Fig. 1 for the Edmond-Carney case and in Fig. 2 for the NormanShawnee and Dodge City cases. For observations from both the Edmond-Carney storm (D2) and the NormanShawnee storm (D3, D5), a three-dimensional grid spacing of $250 \mathrm{~m}$ was used in the Cartesian analysis consistent with $\delta=\Delta / 2$, where $\Delta$ represents the raw spacing of the radar databased on the radial distance from the radar and the width of one radial $\left(1^{\circ}\right)$, and $\delta$ the grid spacing in Cartesian coordinates (Koch et al. 1983). For the Dodge City case, a grid spacing of $100 \mathrm{~m}$ was used in the Cartesian analysis. Although the NormanShawnee storm was significantly closer to KTLX than was the Edmond-Carney storm, 250-m grid spacing was used in both cases to facilitate the comparison of the two storms. A smoothing parameter of $\kappa=0.716 \mathrm{~km}^{2}$ was employed during D2, $\kappa=0.400 \mathrm{~km}^{2}$ was used in D3 and D5, and $\kappa=0.186 \mathrm{~km}^{2}$ was used for the Dodge City case consistent with $\kappa=(1.33 \delta)^{2}$ (Pauley and Wu 1990), each of which were constant throughout each deployment. Additionally, a second-pass convergence parameter $\gamma$ of 0.3 was used (Majcen et al. 2008).

Despite only minor advection within one RaXPol volume with very rapid updates, advection is still accounted for using the mean storm motion of the supercell, which was calculated using locations of the $Z_{\mathrm{DR}}$ column (e.g., Kumjian et al. 2014; Snyder et al. 2015, 2017) as a proxy for updraft motion. 


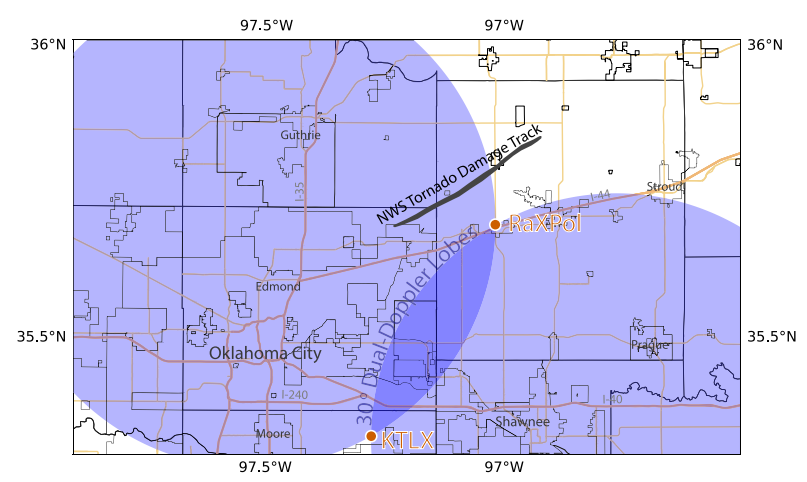

FIG. 1. Overview of RaXPol deployment 2 on 19 May 2013 in which tornado data were collected on the Edmond-Carney supercell and tornado. The dot labeled "RaXPol" corresponds to RaXPol's second deployment and the only overall deployment on this storm. In addition to the $30^{\circ}$ dual-Doppler lobes (blue), the NWS damage swath is also presented (gray) with respect to deployment location. Dual-Doppler analyses were possible throughout roughly the first half of the tornado as it intensified and approached peak intensity.

\section{c. Temporal correction}

The focus of this work was to explore methods of combining WSR-88D and mobile radar datasets for dual-Doppler analyses, including methods that have been frequently used (e.g., Dowell and Bluestein 1997; Wurman et al. 2007a,b; Kosiba et al. 2013). The first method (herein referred to as the "traditional" method) involved choosing the RaXPol volume that was centered in time most closely to the time-centered sweep of the WSR-88D volume (Fig. 3a). By using the mean storm motion for space-to-time conversion, WSR-88D sweeps can be "advected" forward and backward in space to match the RaXPol volume time. In this simplified case, if we choose a midlevel sweep from the WSR-88D data to be the "comparison time" from which the RaXPol volume is selected for use, low-level sweeps must be advected forward while the upper-level sweeps must be advected backward in order to best reproduce the storm as if it were observed at every level instantaneously. The selected RaXPol volume is then also corrected for advection, again using the mean storm motion for time-tospace conversion. Once the volumes have been matched in time, a dual-Doppler synthesis can be constructed from the two datasets.

Although this method provides a straightforward means of correcting the radar volumes for dual-Doppler analysis, one issue in particular detracts from the reliability of these results. No matter how the WSR-88D data are paired with $\mathrm{RaXPol}$ data (i.e., whichever RaXPol volume is chosen for comparison), radar sweeps valid at the same location but with collection times varying by more than $2 \mathrm{~min}$ are invariably being combined. Additionally, assuming a constant advection speed (in time and space) likely results in a nonnegligible source of error, especially when using datasets with such drastic temporal differences (e.g., Chong et al. 1983).

The second method (herein referred to as the "hybrid" method) is designed to reduce temporal and spatial errors by creating hybrid RaXPol volumes using RaXPol sweeps from each of the different volumes occurring within the time span of one WSR-88D volume (Fig. 3b). By utilizing sweeps from multiple RaXPol volumes instead of a single volume, RaXPol sweeps collected at similar times and elevations to the WSR$88 \mathrm{D}$ data are compared, in essence creating a volume that is truly synchronized in time and space with the WSR-88D. This method offers more consistency on a sweep-by-sweep basis, but artificially reduces the temporal resolution of the RaXPol data. Assessment of these two methods revealed very little in systematic differences between the two, which was not surprising (not shown). In both cases, we speculate that factors such as the use of constant advection had substantial negative impacts on the results of the wind synthesis.

The overarching problem with both methods is that they limit the potential temporal resolution of the dualDoppler dataset that could be obtained using a rapid scan radar. While RaXPol provides some of the fastest polarimetric radar updates possible today, the trade-offs necessary to attain such a high scanning rate (e.g., fewer pulses collected per radial) can, at times, result in slightly reduced data quality. If the goal is to utilize the data for dual-Doppler analyses, it makes the most sense to approach the collection of data by either slowing the radar down, which would allow it to synchronize with another radar, or, as examined in the next section, develop a method for preserving the better temporal resolution from RaXPol in the dual-Doppler analysis.

\section{d. Three-dimensional wind synthesis}

The three-dimensional wind field was synthesized within $30^{\circ}$ dual-Doppler lobes for each of the three aforementioned cases (Figs. 1 and 2). Vertical velocities were obtained using upward integration of the anelastic mass continuity equation with a lower boundary condition of $w=0$. Hydrometeor fall velocities are estimated and accounted for in the wind retrieval using an empirical relationship with the radar reflectivity in accordance with Atlas et al. (1973).

\section{Applications of a spatially variable advection correction}

To mitigate errors resulting from the substantial differences in the temporal resolutions of the two datasets, a variational reflectivity tracking scheme [herein referred to as spatially variable advection correction technique 
Norman-Shawnee Tornado 19 May 2013

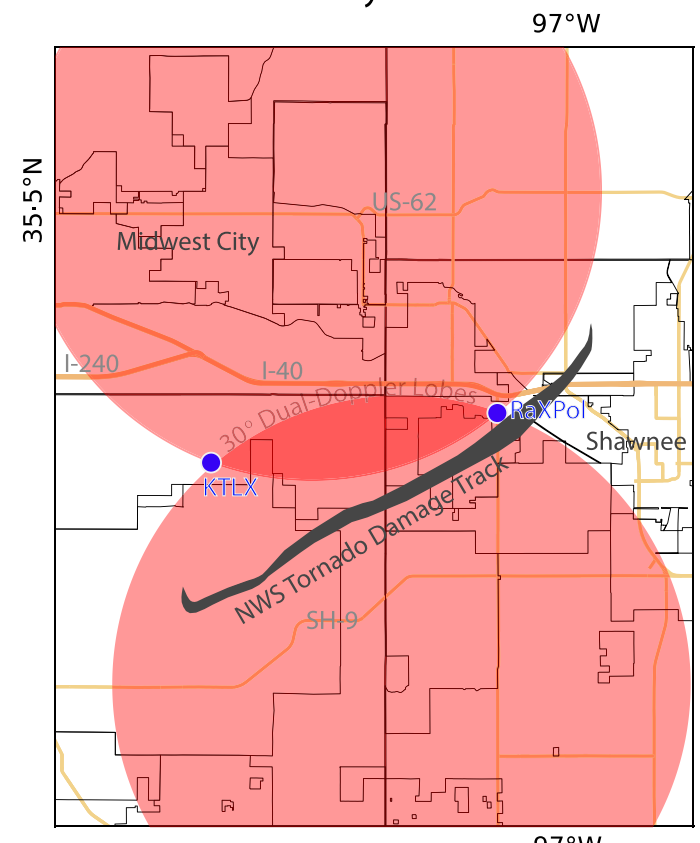

Dodge City Tornadoes

24 May 2016 $100^{\circ} \mathrm{W}$

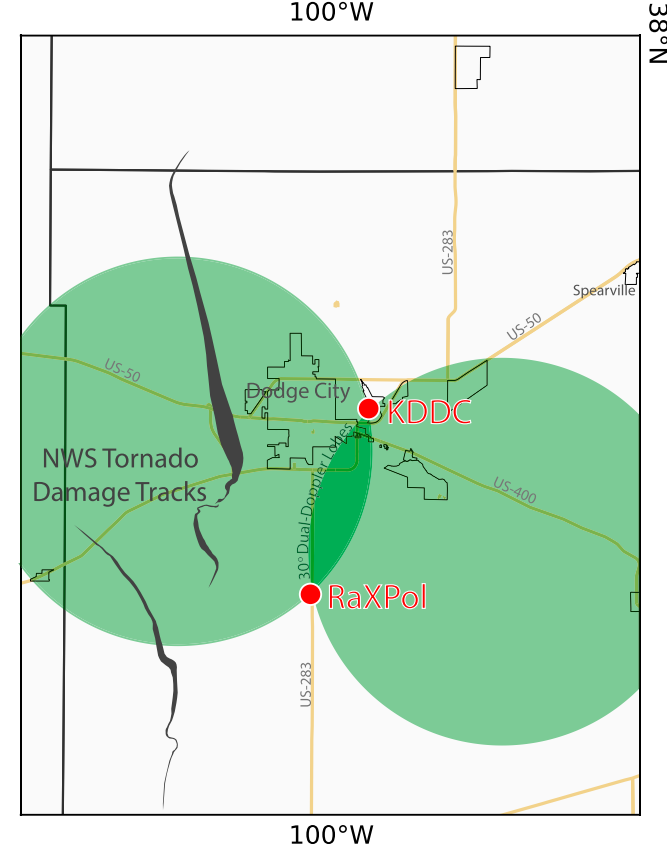

FIG. 2. Overview of the dual-Doppler setups during (left) the Norman-Shawnee tornado (19 May 2013) and (right) the Dodge City tornadoes (24 May 2016). For the Norman-Shawnee case, the location of RaXPol deployment 3 , the first of three deployments on this storm, is labeled with the corresponding $30^{\circ}$ dual-Doppler lobe with KTLX (red). For the Dodge City case, the location of RaXPol deployment 1, which observed approximately eight tornadoes, is labeled just south of Dodge City, along with correspond dual-Doppler lobes with KDDC. In both cases, the locations of the NWS damage survey paths are denoted in gray, for reference.

(SVAC; Shapiro et al. 2010a, b)] was implemented to interpolate (in a Lagrangian sense) the WSR-88D data so that they best matched the RaXPol volumes in time. This technique employs a cost-function minimization, constrained on the frozen-turbulence hypothesis, to calculate the laterally varying horizontal advection fields $U(x, y)$ and $V(x, y)$, which are assumed temporally constant for a particular period of time (in this case the time between two consecutive radar volumes). When applied to reflectivity fields, the frozen-turbulence hypothesis is represented through

$$
\frac{\partial Z_{e}}{\partial t}+U \frac{\partial Z_{e}}{\partial x}+V \frac{\partial Z_{e}}{\partial y}=0
$$

where $Z_{e}$ is the radar reflectivity. Equation (1) states that reflectivity is conserved following horizontal motion during the time interval in which data are collected. Because this is not exactly the case for real radar data, Shapiro et al. (2010a, b) made use of a cost-function minimization with Eq. (1) imposed approximately, that is, as a weak constraint, resulting in the following cost function equation:

$$
\begin{array}{r}
J=\iiint\left[\alpha\left(\frac{\partial Z_{e}}{\partial t}+U \frac{\partial Z_{e}}{\partial x}+V \frac{\partial Z_{e}}{\partial y}\right)^{2}\right. \\
\left.+\beta\left|\nabla_{h} U\right|^{2}+\beta\left|\nabla_{h} V\right|^{2}\right] d x d y d z,
\end{array}
$$

where $U(x, y)$ and $V(x, y)$ are laterally varying advection components and $\alpha=\alpha(x, y, t)$ is a binary "footprint" or "data coverage" function that reflects where the data are located within the domain. The parameter $\beta$ is a constant positive smoothing parameter that is taken to be $100 \mathrm{dBZ}^{2}$ throughout [see Shapiro et al. (2010a, b) for further details]. As a result of the minimization of $J$, we obtain the spatially variable pattern advection fields $U(x, y)$ and $V(x, y)$ along with the advection-corrected $Z_{e}$ field available at any number of user-specified analysis times between two successive volume scan times, but without accounting for the actual storm evolution between WSR-88D volumes as a result of the interpolation.

Shapiro et al. (2010a, b) describe how minimization of cost functions similar to Eq. (2) had been used in many previous studies as single-Doppler velocity retrieval 

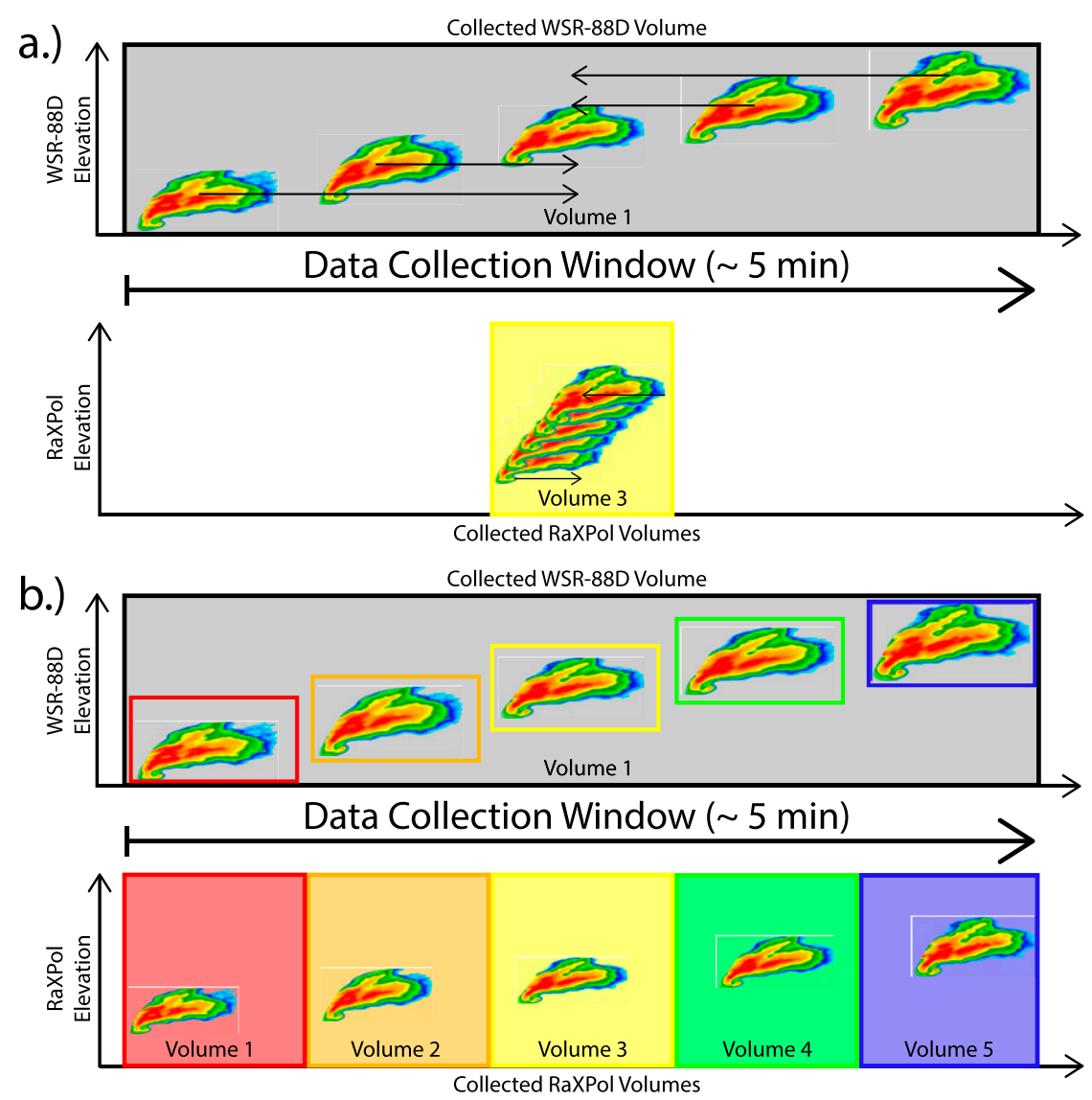

FIG. 3. Simplified schematic representing two methods of combining radar datasets for dual-Doppler analysis. (a) Data from the WSR-88D are advected forward and backward in time to best match a single volume from RaXPol (volume 3). Data at each elevation are considered to be collected simultaneously and are corrected using a constant advection velocity for time-to-space conversion. (b) Data from separate RaXPol volumes are paired with data from the WSR-88D valid in both time and space to create a new, "hybrid" volume. Colored boxes in (b) represent individual sweeps from the WSR-88D with which RaXPol sweeps are paired. For reference, the time in which one WSR-88D scan takes place is on the abscissa, and change in scanning elevation is on the ordinate.

algorithms (i.e., where $U$ and $V$ were interpreted as actual air velocity components rather than patterntranslation components), noting mixed results with that particular application (e.g., Laroche and Zawadzki 1994; Germann and Zawadzki 2002; Liou 2002; Kramar et al. 2005; Houser 2013). Shapiro et al. (2010a, b) then showed how the same technique could be repurposed with the goal of spatially variable advection correction of radar data with $U(x, y)$ and $V(x, y)$, now interpreted as pattern translation components. This technique, as is demonstrated herein, can be adapted to improve the dual-Doppler analysis by helping to mitigate temporal errors that arise from nonsynchronized radars.

In experiments with Terminal Doppler Weather Radar and WSR-88D data, Shapiro et al. (2010a,b), found the SVAC technique to be more accurate than using even the optimal constant advection velocity (which was determined empirically). In our study, we utilize the SVAC technique to interpolate the radar data between two volumes, effectively synchronizing the RaXPol and WSR-88D datasets. Additionally, employing SVAC allows for preservation of the temporal resolution obtained by RaXPol, which provides the short time steps necessary for more frequent dual-Doppler analyses (i.e., equivalent to RaXPol's volumetric update interval).

The same general technique that was applied to interpolate reflectivity data in time can also be applied directly to radial velocity and $Z_{\mathrm{DR}}$ data to create interpolated radial velocity and $Z_{\mathrm{DR}}$ fields valid at any desired analysis time between the two data input times. However, one should be aware of one potential caveat: because radial velocity measurements are dependent 


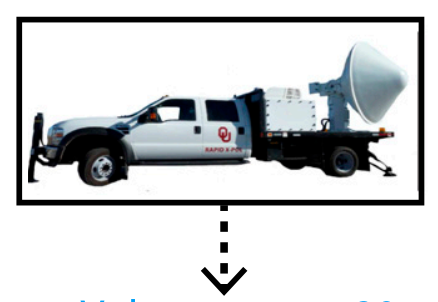

\begin{tabular}{|l|ll|}
\hline RaXPol & RADAR & WSR-88D \\
\hline $20 \mathrm{~kW}$ & Peak Transmit Power & $475 \mathrm{~kW}$ \\
\hline $9.73 \mathrm{GHz}$ & Operating Frequency & $2.91 \mathrm{GHz}$ \\
\hline $1.0^{\circ}$ & Beamwidth (one-way, $3 \mathrm{~dB})$ & $0.91^{\circ}$ \\
\hline Varies & Range Resolution & $250 \mathrm{~m}$ \\
\hline $180^{\circ} \mathrm{s}^{-1}$ & Antenna Rotation Rate & $30^{\circ} \mathrm{s}^{-1}$ \\
\hline \hline
\end{tabular}
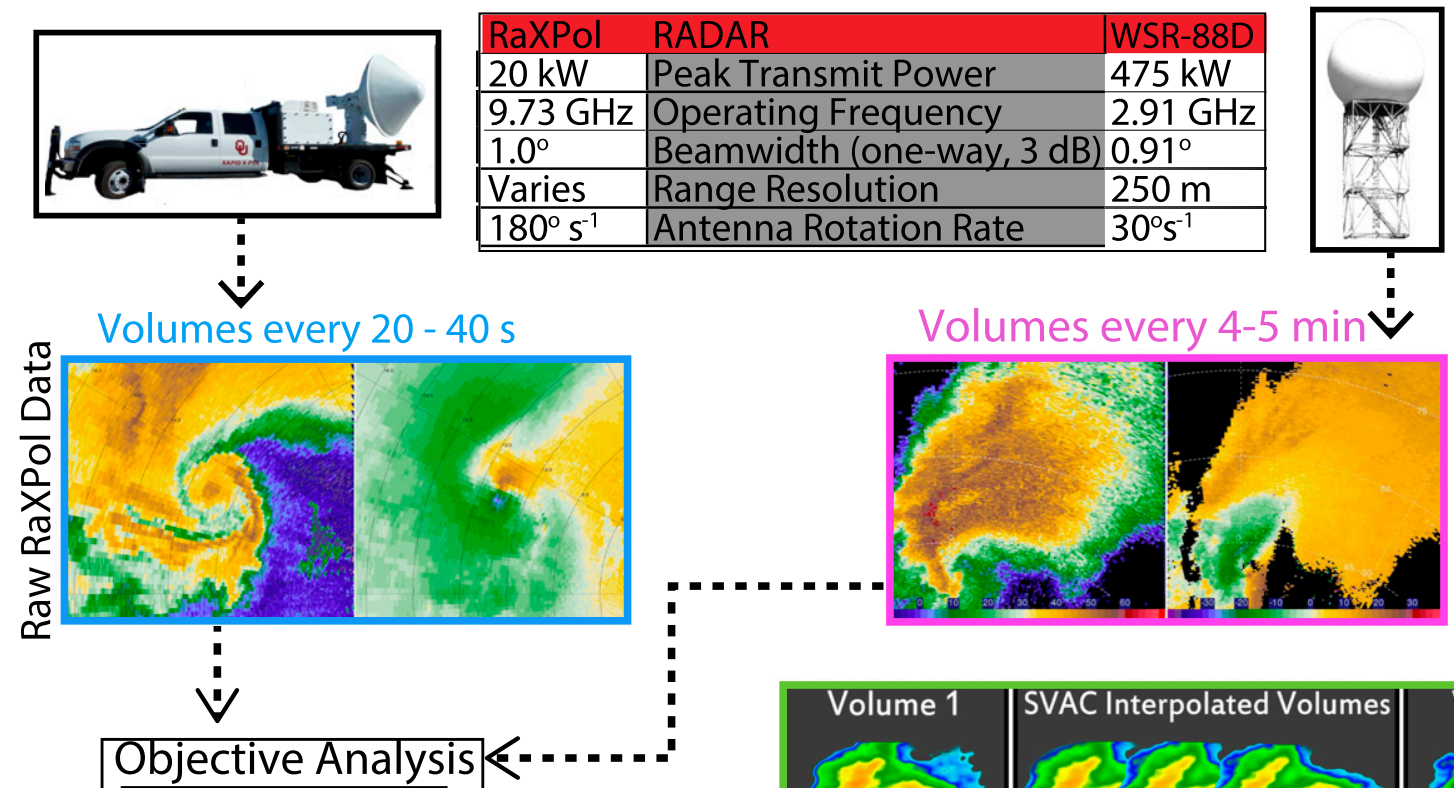

Observation Processing and Wind Syntheses (OPAWS) (e.g., Kosiba et al. 2013) was used to map the data to a Cartesian grid using a two-pass Barnes analysis, and a grid spacing of $250 \mathrm{~m}$.
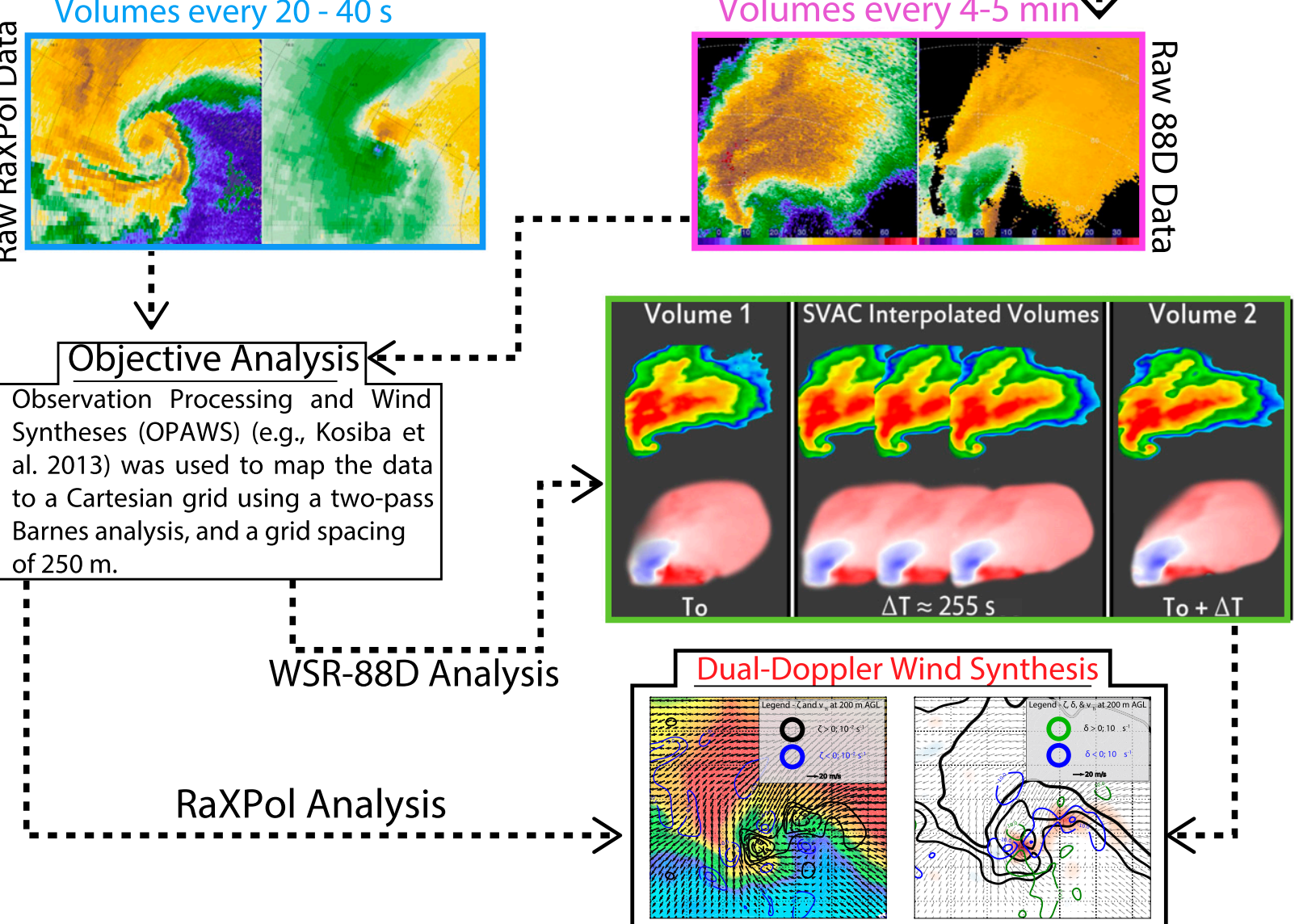

FIG. 4. Step-by-step diagram of the data processing in which the spatially variable advection correction technique was utilized to create time-synced, quasi-rapid scan dual-Doppler analyses between RaXPol and a WSR-88D. Once the data are quality controlled and objectively analyzed, the WSR-88D data are interpolated in time to best "match" the volumes collected by RaXPol. The time-interpolated volumes are then paired with data collected from RaXPol and the 3D wind field synthesized.

upon the viewing angle of the radar with respect to features of interest (e.g., tornado/mesocyclone), the features must maintain sufficient distance from the WSR-88D such that the viewing angle of the radar is not substantially altered over one interpolation period. Equivalently, the interpolation period must be reasonably short (i.e., $<10 \mathrm{~min}$ ). For each of the three cases considered here, the storms ranged from 10 to $40 \mathrm{~km}$ from the WSR-88D, all with volume update times of $\sim 250 \mathrm{~s}$.

After interpolating both radial velocity and reflectivity, individual time steps were combined together to create new "pseudovolumes," then paired with the corresponding
RaXPol volume to complete the dual-Doppler wind synthesis. A schematic illustrating the process, from data collection through 3D wind synthesis, is outlined in Fig. 4.

\section{Results}

To evaluate the effectiveness of the SVAC technique, we focus on the Edmond-Carney storm because it maintained a distance sufficient for both dual-Doppler analysis of the tornado and complete vertical sampling of the $Z_{\mathrm{DR}}$ column, which is leveraged for comparisons with the dual-Doppler-obtained vertical velocity field. 


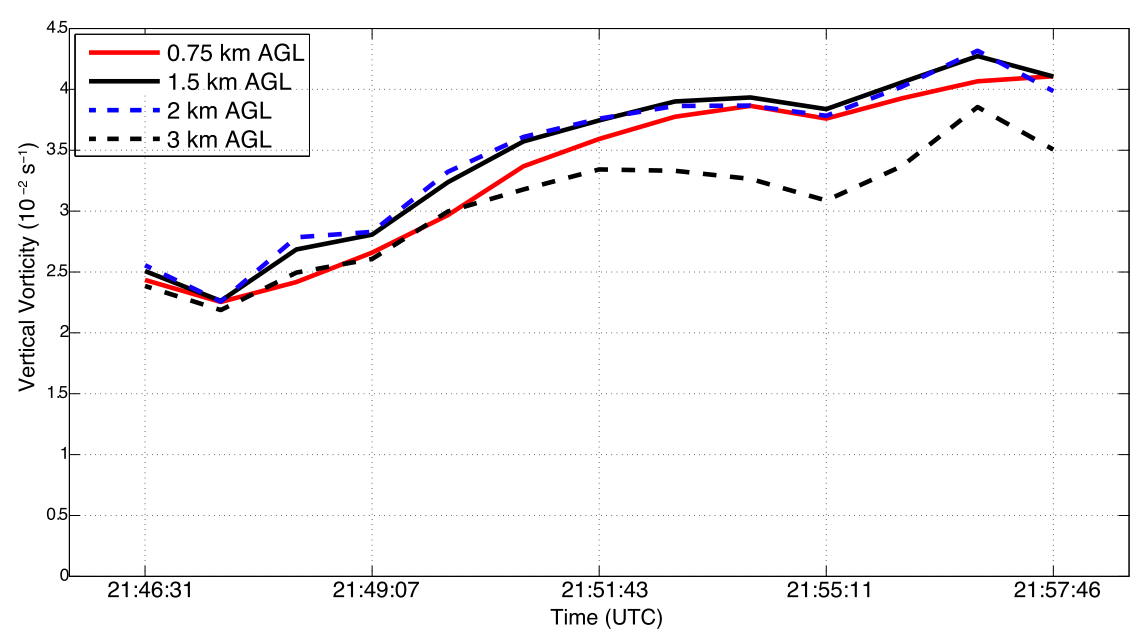

FIG. 5. Vertical vorticity time series from the Edmond-Carney tornado on 19 May 2013 at four selected levels obtained from SVAC analysis technique.

The same observations were unavailable in the Dodge City and Norman-Shawnee cases since the storms passed very close to the WSR-88D, resulting in a lack of continuous $^{2}$ data topping the $Z_{\mathrm{DR}}$ column.

\section{a. The Edmond-Carney supercell on 19 May 2013}

The first of two RaXPol-observed tornadoes on 19 May 2013 was rated EF-3 near Carney, Oklahoma. Although the nearest WSR-88D (KTLX) was more than $30 \mathrm{~km}$ from the storm at all times in which RaXPol was simultaneously collecting data, the distance allowed for broad dual-Doppler lobes to gain a more complete picture of the storm, especially at upper levels. To assess the performance of the SVAC technique directly, the evolution of vertical vorticity in the storm (diagnosed from singleDoppler radial velocity analyses) and changes in the $Z_{\mathrm{DR}}$ column with respect to vertical velocities were examined and compared to those determined from both traditional and hybrid dual-Doppler methods (Figs. 3a and 3b). This section demonstrates that temporal synchronization between two datasets using SVAC offers value over the traditional and hybrid methods discussed earlier.

\section{1) Vertical VORTICITY ANALYSES}

RaXPol data collection began at $\sim 2145$ UTC, approximately $90 \mathrm{~s}$ after tornadogenesis, and captured the intensification of the tornado as it moved across central

\footnotetext{
${ }^{2}$ As the storm moved over the WSR-88D, the maximum radar elevation used was not sufficient to top the $Z_{\mathrm{DR}}$ column, or at times would only observe a small "slice" of the column. The $Z_{\mathrm{DR}}$ column analyses throughout these time periods were unreliable for this reason, and thus not considered in this study.
}

Oklahoma. Dual-Doppler analyses of the low-level vortex depict an expected intensification despite insufficient horizontal resolution to resolve the tornado itself throughout a period in which the tornado was observed to intensify. Between 2146:31 and 2157:46 UTC (Fig. 5), the vortex slowly intensified as the tornado and mesocyclone approached their peak intensities. Though analyses are unavailable when the tornado damage was greatest, the steady intensification in both single-Doppler radial velocity analyses and in vertical vorticity time series verifies that the vortex was strengthening throughout the observing period.

Initially, the results of the traditional and SVAC methods were directly compared to identify any regions of systematic error (Fig. 6). Although there were no substantial differences initially between the techniques, the traditional method yields a slightly weaker and broader tornado vortex, which is likely a result of discrepancies in volume synchronization. Utilization of the SVAC method to interpolate the volume in time between two consecutive volumes makes synchronization between the WSR-88D volume and the RaXPol volume trivial, but with the caveat that changes to the storm's structure as a result of intervolume evolution are not accounted for. In addition, the SVAC method also allows for output at intervening time steps resulting from the temporal interpolation between two consecutive WSR-88D volumes, making dual-Doppler analyses possible for each volumetric update obtained by RaXPol. In this case, analyses are obtained at 2150:51,2151:43, and 2152:35 UTC as well as 2149:07 and 2153:27 UTC, resulting in much greater temporal resolution than the traditional method (Fig. 6).

The results of the three dual-Doppler analyses were similar to each other and all depicted similar evolution 


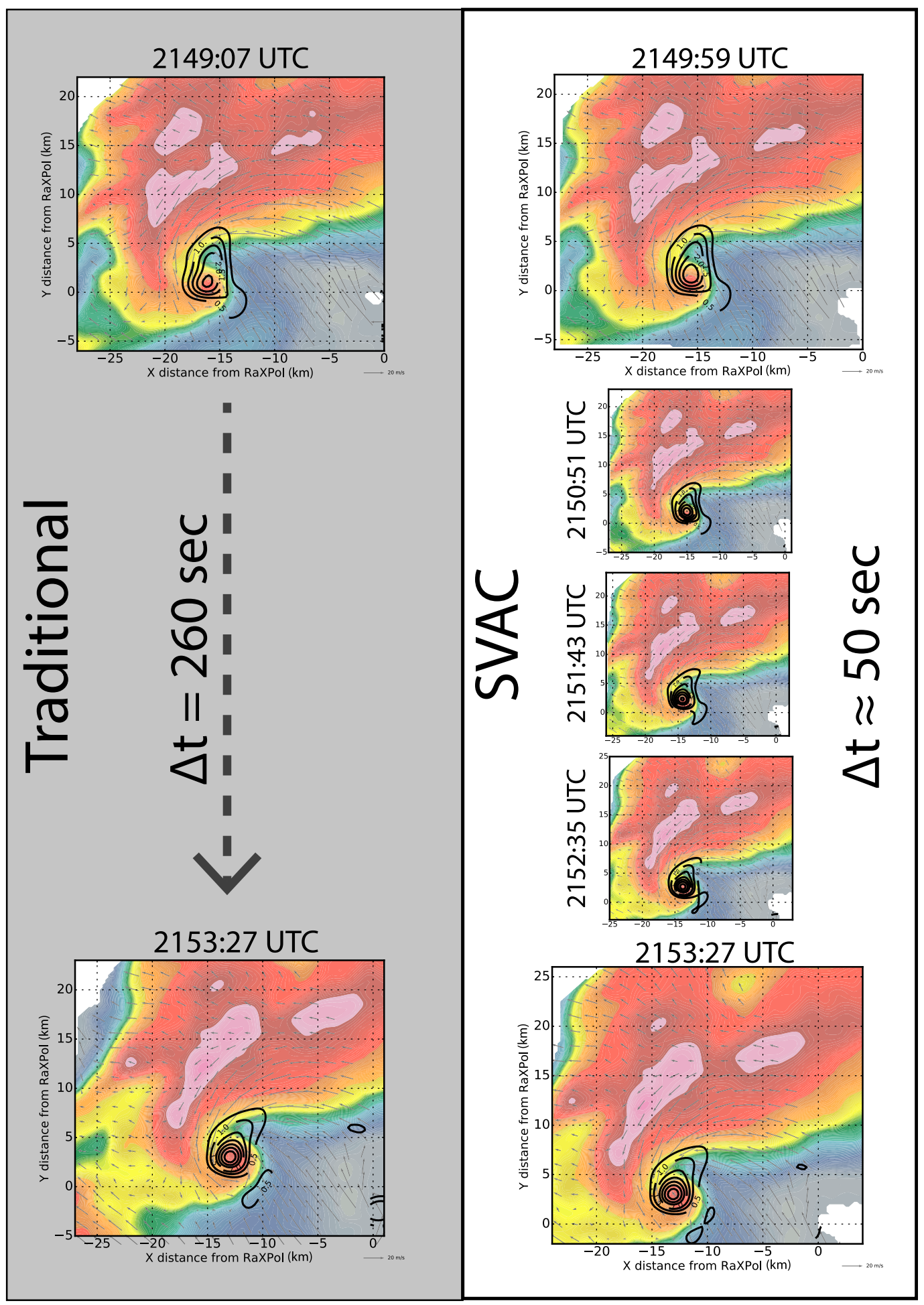

FIG. 6. Dual-Doppler analyses from the 19 May 2013 Edmond-Carney supercell derived from (left) traditional and (right) SVAC methods spanning one WSR-88D volume (2149:07-2153:27 UTC) and the corresponding SVAC volume with select intermediate times included to demonstrate the evolution captured through temporal interpolation of the WSR-88D volume. 


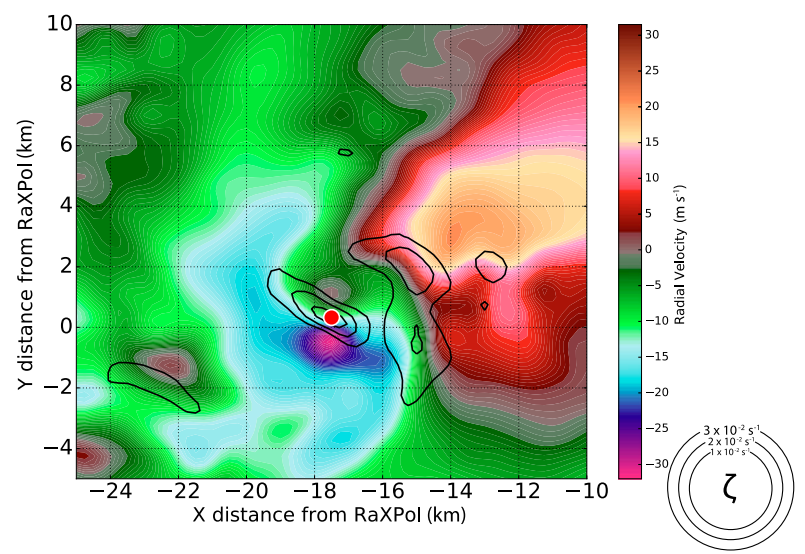

FIG. 7. RaXPol radial velocity at an arbitrary time (2148:15 UTC, 19 May 2013 Edmond-Carney supercell; color contoured) overlaid with axisymmetric vertical vorticity calculated from radial velocity data. Axisymmetric vertical vorticity is used as a proxy to determine the "true" tornado center (red dot) from single-Doppler data for comparison to dual-Doppler analyses.

of the storms based on single-Doppler observations, but additional methods of error assessment were necessary to evaluate the SVAC analyses against the traditional and hybrid methods. One method involved using comparisons of the tornado vortex locations in singleDoppler data to the location of the low-level vorticity maximum in the dual-Doppler analysis. From RaXPol data, the center of the vortex can be estimated at every analysis time by utilizing radial velocity data to calculate the axisymmetric vertical vorticity maximum (Fig. 7). To reduce the chance that natural radial velocity variance would result in a misidentification of the tornado's center, the algorithm was limited to a prescribed domain immediately surrounding the tornado. The dualDoppler vortex centers were then calculated and plotted with respect to the vortex identified in RaXPol data.

By assuming that the tornado is occurring at the location of the vertical vorticity maximum in a dual-Doppler analysis, a direct comparison can be made among the locations of the vortex in each of the analyses from the traditional, hybrid, and SVAC methods. Based on scatterplots of the vortex locations (Fig. 8) it is concluded that, in general, the advection-corrected volumes yield better agreement overall with the true vortex locations, although there are significantly more advection-corrected members (22) than members of the traditional/hybrid methods (5). To visualize how each method performed as a function of height, the magnitudes of the mean displacement of each analyzed vortex center from the true vortex center were plotted with height above ground level (Fig. 9). One problem with assessing all of these datasets with respect to a "truth" obtained through RaXPol data alone is that all three dual-Doppler methods use the
RaXPol data as one of the two datasets used to synthesize the $3 \mathrm{D}$ wind field. To address this issue, the location of the vortex in the interpolated WSR-88D data was calculated in the same way as for RaXPol data and used for additional verification.

In each of the four cases, there is a clear distinction between the advection-corrected datasets and the hybrid/traditional methods. The advection-corrected volumes are both particularly well behaved with height, the maximum displacements are both very near the surface, and aloft near the top of the domain. The SVAC singleDoppler data and dual-Doppler syntheses are nearly parallel to one another with height and exhibit a nearly constant vortex displacement, an unsurprising result since the single-Doppler data are a component of the dual-Doppler analyses (Fig. 9). In addition, a quasisteady standard deviation between 0.6 and $0.8 \mathrm{~km}$ provides confidence that the scheme is producing reliable results provided that the vortex is in nearly the correct location consistently with time and height. Analyses from the traditional and hybrid methods were not nearly as well behaved as those to which advection correction was applied; results from the traditional and hybrid methods exhibit maximum displacements near the surface, with decreasing displacement with height. In general, there was a tendency for the tornado center displacements to decrease above $1 \mathrm{~km}$, and the traditional method even produces a slightly better vortex position than those using the advection-corrected scheme near $1.5 \mathrm{~km}$ and between 2.5 and $3.5 \mathrm{~km}$ AGL (Fig. 10b) owing to true synchronization of the RaXPol and WSR-88D datasets at these times. Unfortunately, standard deviations of the vortex position ranging from $0.5 \mathrm{~km}$ to greater than $1.5 \mathrm{~km}$ does not provide confidence in the location of the vortex from scan to scan, especially in the hybrid case, which at times is characterized by standard deviations greater than the horizontal scale of the tornado vortex.

The results indicate that the hybrid method, which was attempted in hopes of replicating two synchronized radars, was substantially worse than both the traditional and SVAC methods of dual-Doppler analysis. However, despite some considerable differences in both advectioncorrected data and the traditional methods, a number of observations can be drawn from both sets of results. Both the SVAC and traditional dual-Doppler methods suffered from the largest vortex displacement near the surface, which decreased with height likely as a result of extrapolation errors below the minimum beam height, which was roughly $600 \mathrm{~m}$ in this case. Thus, any data below the 750-m grid point are more susceptible to error, but are included in the analysis specifically for the purpose of estimating the geographical location of the vortex at the 

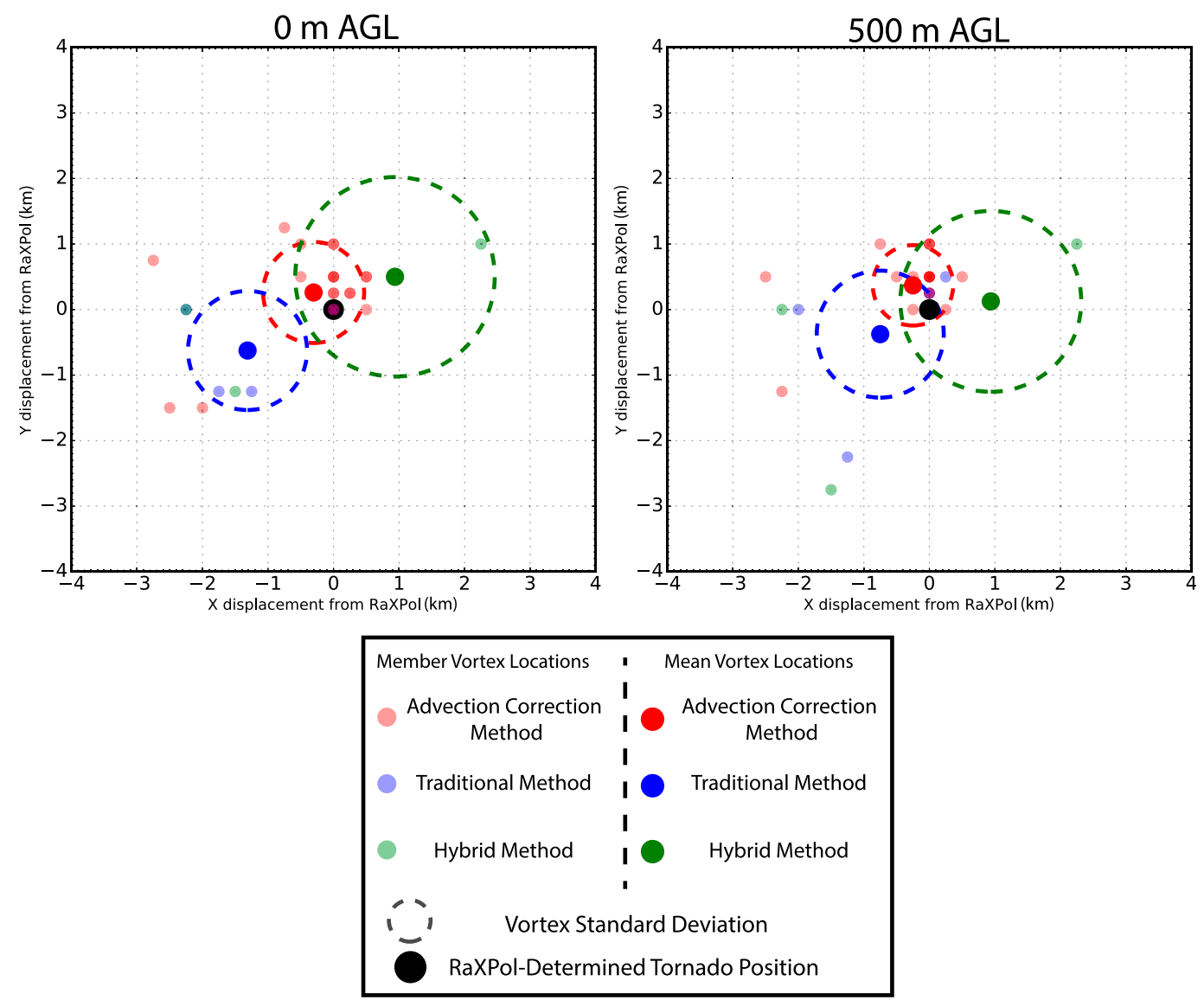

FIG. 8. Dual-Doppler-derived vortex displacement plots from the 19 May 2013 Edmond-Carney supercell showing two example levels: (left) 0 and (right) $500 \mathrm{~m}$ AGL. The "true" tornado vortex location, obtained from RaXPol radial velocity data, is adjusted to the origin and the relative distances from the RaXPol vortex center are shown. Small dots represent individual dual-Doppler members, while the large dots represent the mean of all members at each particular level.

surface and are not otherwise considered in any quantitative manner. Above $750 \mathrm{~m}$, both the displacements of the vortex and the standard deviations of the displacements decrease, especially in the SVAC and traditional cases. Both the traditional and SVAC methods resulted in vortex displacements slightly less than $1 \mathrm{~km}$ on average for all times and heights. While this still seems large, it is important to consider that for a radar observing a storm from $40 \mathrm{~km}$ (as KTLX was doing in this case), the radar's $3-\mathrm{dB}$ beamwidth is nearly $0.7 \mathrm{~km}$. Additionally, data processing, including smoothing and mapping to a coarser horizontal grid, likely contributed to the vortex displacements observed in Figs. 9 and 10 as well.

To facilitate further assessment of these datasets, the National Weather Service (NWS) damage survey from the Edmond-Carney tornado provides another basis for comparison to a ground-based truth. From each of the four analysis methods utilized in Figs. 8-10, we compare the coordinates of the vorticity maxima at the surface with the NWS ground survey, which provides a geographical truth for comparison (Fig. 11). Despite potentially compounded errors caused by extrapolation in each of the four panels, the SVAC dual-Doppler method results in the best agreement between the obtained vertical vorticity maxima and the tornado damage path. The vortex is generally located on the north side of the tornado track for all times, which is expected since tornado damage is generally greatest on the south side of an eastwardtranslating vortex, owing to the alignment of the storm motion vector with the azimuthal winds around the tornado $\left(u \approx 12.6 \mathrm{~m} \mathrm{~s}^{-1}\right.$; e.g., Fujita et al. 1970; Mahale et al. 2012). Alternatively, extrapolation of a northward-tilting vortex to the surface could have also resulted in the observed northward bias of the vortex location with respect to the damage path (i.e., extensive northward tilt of the vortex in the lowest levels is underestimated in the extrapolation of data to the surface). 


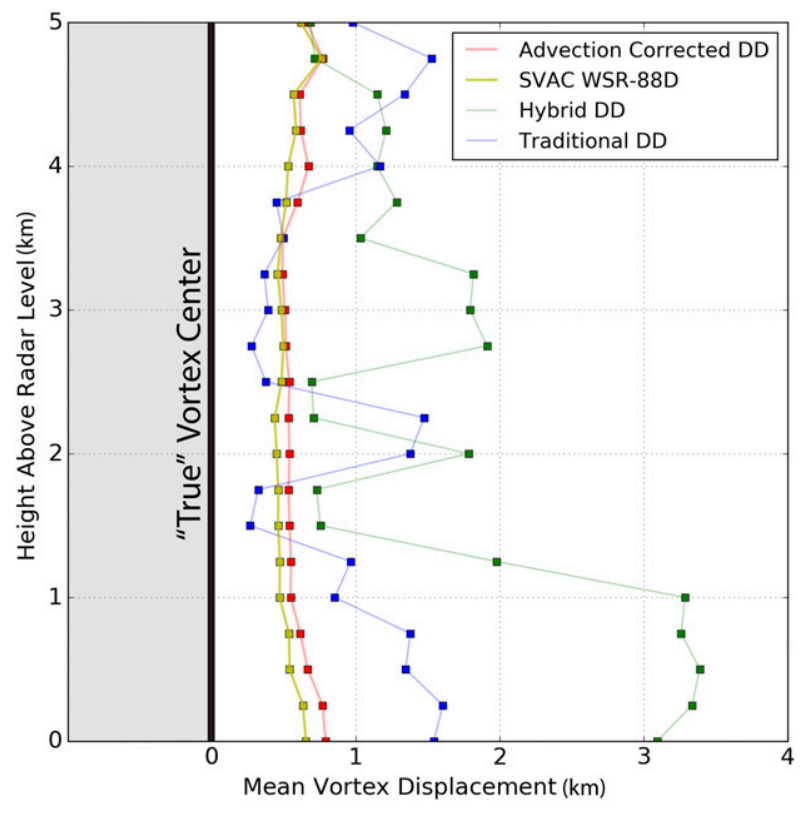

FIG. 9. Mean vortex displacement magnitude vs height for the advection-corrected dual-Doppler (red), spatially variable advection corrected WSR-88D single-Doppler data (yellow), hybrid dual-Doppler (green), and traditional dual-Doppler (blue) methods from the 19 May 2013 Edmond-Carney supercell. Each displacement is relative to the location of the tornado vortex obtained from RaXPol data, which is adjusted to the origin and is represented by the thick black line.

While both the SVAC and traditional methods likely suffered from similar sources of error (e.g., extrapolation and errors resulting from the radar beamwidth), the SVAC method generally produces the most precise geographical alignment of features. In addition to offering more frequent dual-Doppler output, the ability to synchronize the datasets effectively lends confidence in the minimization of errors associated with the analysis.

\section{2) $Z_{\mathrm{DR}}$ COLUMN ANALYSIS}

As an added benefit, both radars possessed polarimetric capabilities, allowing for direct comparison of storm microphysical characteristics to the SVACobtained 3D wind field and aiding in the assessment of the derived vertical velocity field. One such microphysically relevant feature is the $Z_{\mathrm{DR}}$ column, an upward extension of enhanced $Z_{\mathrm{DR}}$ associated with the lofting of liquid raindrops and the presence of mixedphase hydrometeors (e.g., Illingworth et al. 1987; Bringi et al. 1991; Hubbert et al. 1998; Kennedy et al. 2001; Loney et al. 2002). These $Z_{\mathrm{DR}}$ columns can lend many uses to our understanding of severe storms, such as providing a method of estimating a storm's mean motion vector instead of attempting to track other easily identifiable features that are often highly nonlinear (e.g., hook echoes/tornadoes). Additionally, the relationship between $Z_{\mathrm{DR}}$ columns and updraft intensity has been recently established in simulations of nonsupercell storms (e.g., Kumjian et al. 2014; Snyder et al. 2015); however, there are limited observations of the correlation between updraft structure and intensity and $Z_{\mathrm{DR}}$ column properties in supercells, largely owing to dangers of collecting in situ data in supercells and difficulties in estimating updraft properties from radar observations
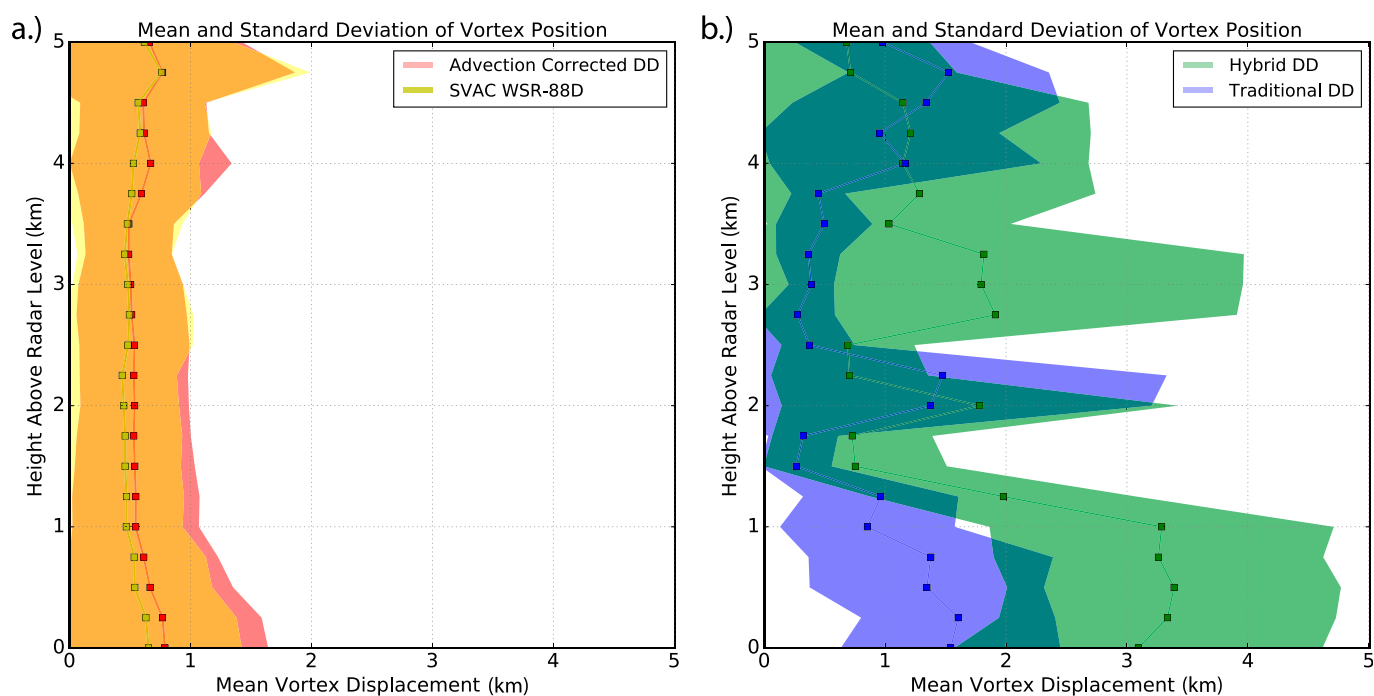

FIG. 10. The mean vortex displacement vs height profiles of (a) advection-corrected dual-Doppler and SVAC WSR-88D data and (b) hybrid dual-Doppler and traditional dual-Doppler from the 19 May 2013 Edmond-Carney supercell. Transparent color filling represents the standard deviation of each profile with the same corresponding color and based on individual member data, similar to the scatterplots in Fig. 8. Note that this figure is broken into two panels but contains the same displacement profiles as Fig. 9. 

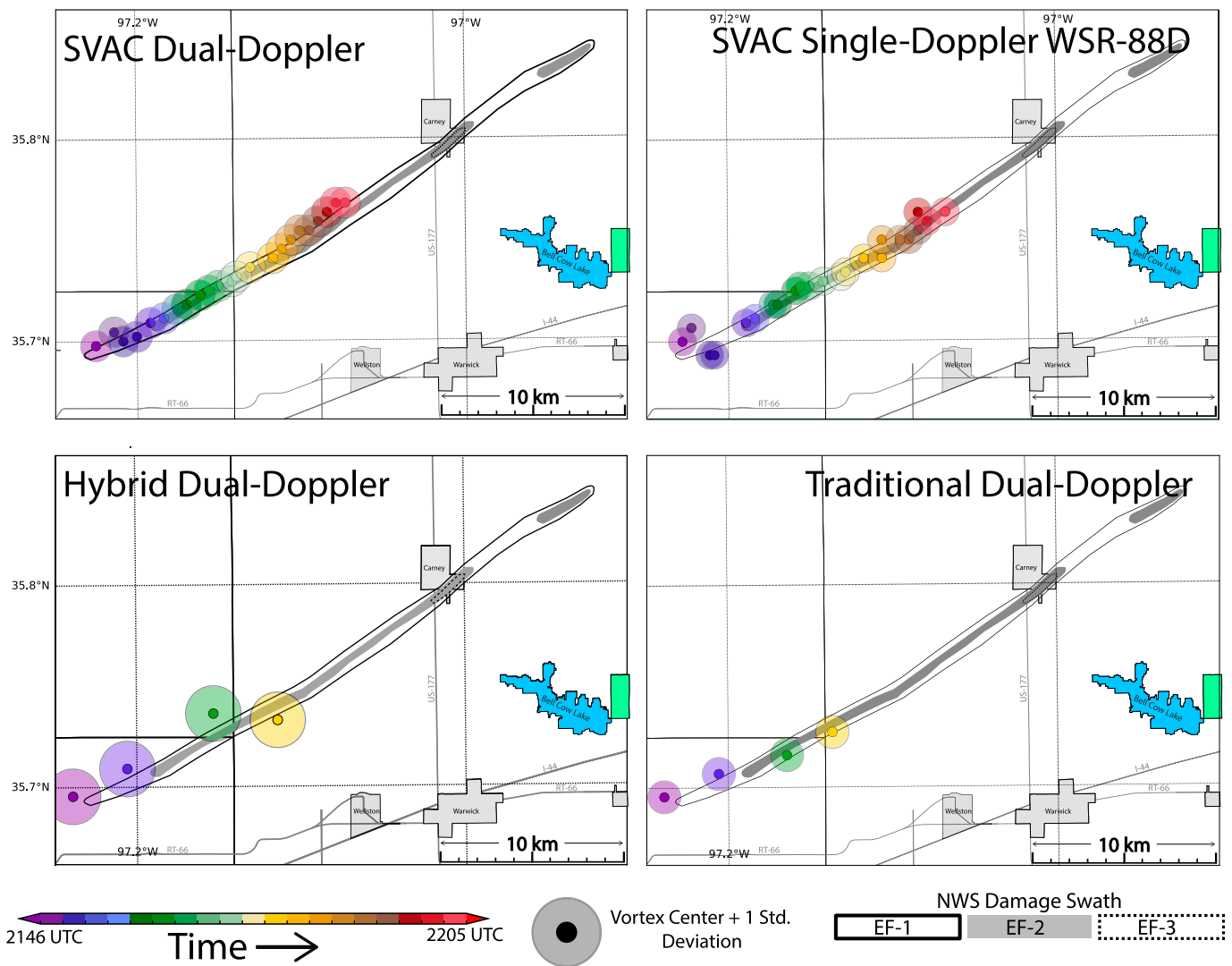

FIG. 11. Tornado vortex track of the Edmond-Carney tornado from the (top left) SVAC dual-Doppler method, (top right) SVAC single-Doppler retrieval, (bottom left) hybrid method, and (bottom right) traditional method. The solid dots represent the vortex location based on the maximum vertical vorticity at the surface, and the larger, transparent circles represent the standard deviation of the vortex location at the surface based on all members in each method. The dots and circles are color coordinated based on the time of the observation. In addition, the vortex locations are overlaid on the NWS damage survey tornado track for spatial comparison.

(e.g., Bringi et al. 1997; Crowe et al. 2009; Kumjian et al. 2014; Tanamachi and Heinselman 2016). In the EdmondCarney case, KTLX captured the $Z_{\mathrm{DR}}$ column with complete vertical continuity throughout the entirety of its evolution. Thus, these data, interpolated using the same SVAC technique described in section 4 , are used only to help qualitatively assess the dual-Doppler-derived vertical velocity field obtained via the SVAC method.

Throughout most of the observation period of the Edmond-Carney storm, the supercell possessed a clear $Z_{\mathrm{DR}}$ column ${ }^{3}$ roughly coincident with the main updraft

\footnotetext{
${ }^{3}$ In accordance with the formal definition of $Z_{\mathrm{DR}}$ column (e.g., Kumjian et al. 2014), a $Z_{\mathrm{DR}}$ column is an extension of positive $Z_{\mathrm{DR}}$ above the environmental $0^{\circ} \mathrm{C}$ level. In this case, analyses of $Z_{\mathrm{DR}}$ are available only below the environmental $0^{\circ} \mathrm{C}$ level (Fig. 11). However, the processes responsible for a $Z_{\mathrm{DR}}$ column are identical to those that occur below the environmental $0^{\circ} \mathrm{C}$ level; thus, the region of relatively higher $Z_{\mathrm{DR}}$ will still be referred to as a $Z_{\mathrm{DR}}$ column.
}

(Fig. 12). In this case, initial alignment between the $Z_{\mathrm{DR}}$ column and the updraft, and knowledge of previous studies of $Z_{\mathrm{DR}}$ columns (e.g., Scharfenberg et al. 2004; Kumjian et al. 2014; Snyder et al. 2015) prompted further investigation into how observations of the $Z_{\mathrm{DR}}$ column compared with the vertical velocity field obtained from our analysis. At 2148:15 UTC (Fig. 12a), $Z_{\mathrm{DR}}$ in excess of $2 \mathrm{~dB}$ at $2.5 \mathrm{~km}$ AGL closely coincides with the regions of largest vertical velocity. In addition to similarities between the intensity of the updraft and $Z_{\mathrm{DR}}$, the shape of the updraft also closely resembles the shape of the enhanced $Z_{\mathrm{DR}}$ field, further suggesting that the updraft is directly responsible for the growth of hydrometeors within this region. However, despite the likely association between the updraft and growth of drops within this region, the maximum $Z_{\mathrm{DR}}$ and maximum updraft do appear to be slightly offset from one another. Superimposition of the horizontal wind vectors with vertical velocity and $Z_{\mathrm{DR}}$ (Figs. 12d-f) reveals an upwind displacement of the updraft from 

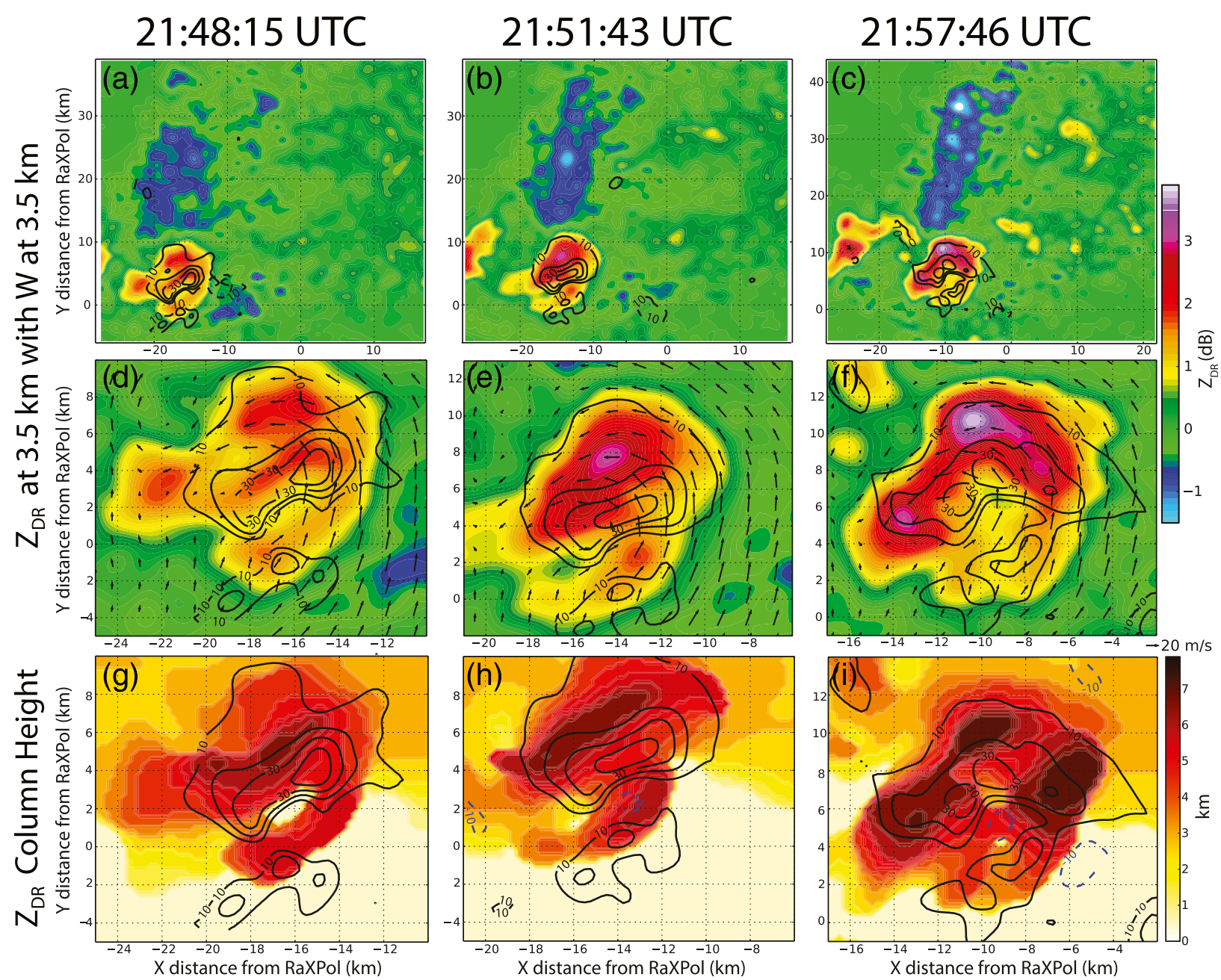

FIG. 12. Comparisons of the vertical wind field derived through dual-Doppler analyses and $Z_{\mathrm{DR}}$ obtained from the KTLX WSR-88D at three times spanning RaXPol deployment 2 when the 19 May 2013 Edmond-Carney tornado was ongoing: (a)-(c) wide view of $Z_{\mathrm{DR}}$ and vertical velocity at $3.5 \mathrm{~km}$ AGL (contoured in black every $10 \mathrm{~m} \mathrm{~s}^{-1}$ ) provided for scale perspective of both the updraft size and $Z_{\mathrm{DR}}$ column size and shape; (d)-(f) as in (a)-(c), but zoomed in on the $Z_{\mathrm{DR}}$ column with horizontal wind vectors superimposed; and (g)-(i) $Z_{\mathrm{DR}}$ column height and vertical velocity at $3.5 \mathrm{~km}$ AGL (black contours positive, dashed blue contours negative; every $10 \mathrm{~m} \mathrm{~s}^{-1}$ ). Note that the top of the $Z_{\mathrm{DR}}$ column is considered to be the level where $Z_{\mathrm{DR}}$ falls below $1 \mathrm{~dB}$.

the largest $Z_{\mathrm{DR}}$ and maximum $Z_{\mathrm{DR}}$ column height (Figs. 12g-i). This finding suggests that as the hydrometeors grow within the updraft, they are displaced slightly downstream from the center of the updraft in the direction of the storm-relative winds, an observation that has been well documented in the past (e.g., Conway and Zrnić 1993; Kennedy et al. 2001; Loney et al. 2002; Kumjian and Ryzhkov 2008). ${ }^{4}$ The 2148: 15 UTC analysis provides visual representation of the

\footnotetext{
${ }^{4}$ Both Conway and Zrnić (1993) and Kennedy et al. (2001) compared vertical velocities obtained from dual-Doppler analysis to $Z_{\mathrm{DR}}$ columns, but with coarser spatial and temporal resolution than is examined here.
}

updraft shape and its manifestation in $Z_{\mathrm{DR}}$, with the exception of the western periphery of the updraft, where the strongest vertical velocities are absent but $Z_{\mathrm{DR}}$ remains high.

Throughout the entirety of the Edmond-Carney $Z_{\mathrm{DR}}$ analysis, locations of the highest vertical velocities correspond closely, but are slightly displaced from, maxima in $Z_{\mathrm{DR}}$ (Fig. 12). In general, the regions of updraft and higher $Z_{\mathrm{DR}}$ tended to closely follow one another as the storm translated through the domain, which is observed both qualitatively and quantitatively (Fig. 13). Regions of higher $Z_{\mathrm{DR}}$ correspond to stronger updrafts, presumably as a result of size sorting and perhaps faster drop growth. Not only does the maximum in $Z_{\mathrm{DR}}$ correspond well with 

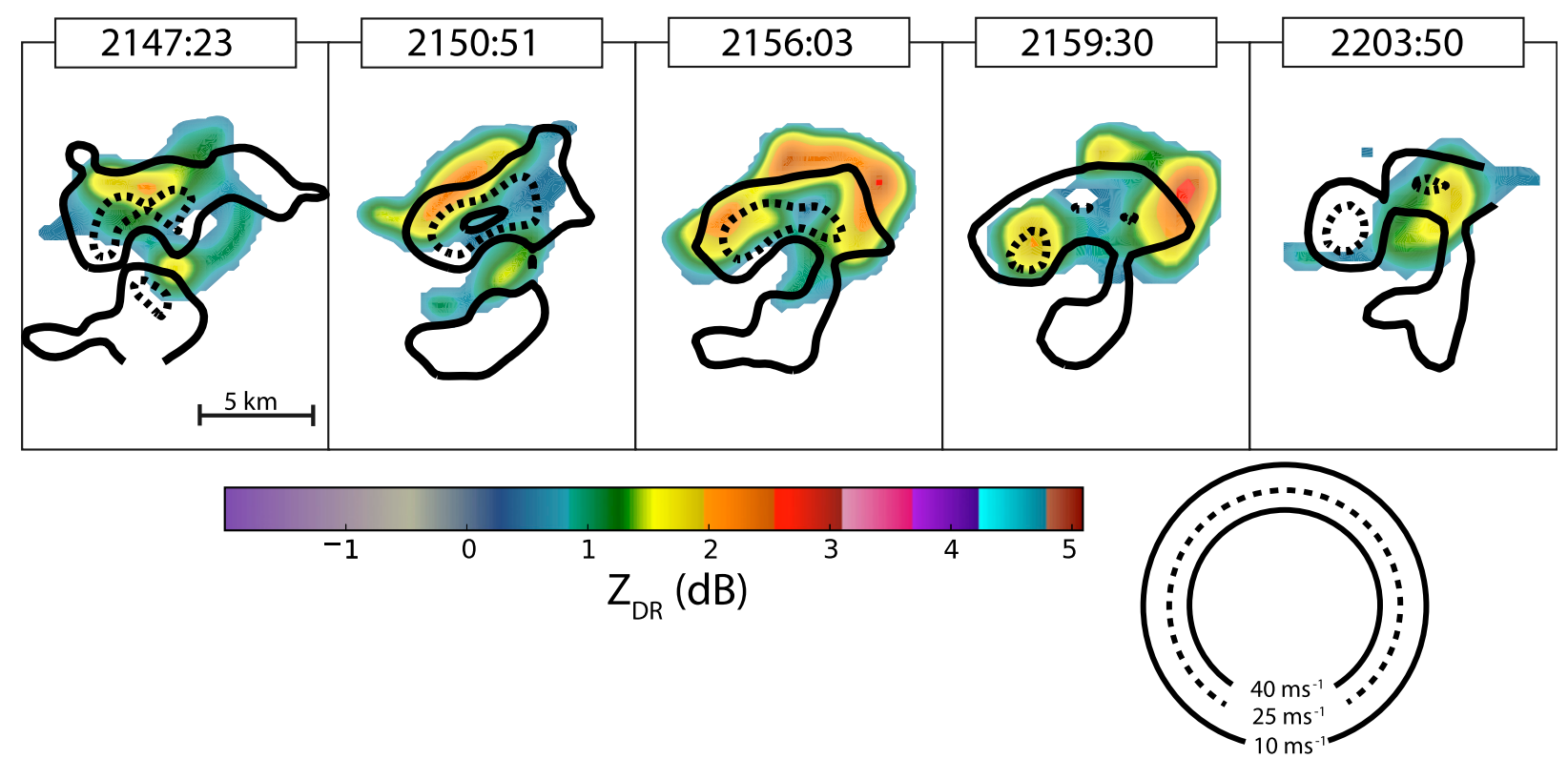

FIG. 13. Comparison of the $Z_{\mathrm{DR}}$ column with respect to the storm updraft. The $Z_{\mathrm{DR}}$ column is color contoured and vertical velocity is contoured in black at intervals of 10,25 , and $40 \mathrm{~m} \mathrm{~s}^{-1}$ to offer a quantitative depiction of the updraft with respect to $Z_{\mathrm{DR}}$ as the two evolve in time.

the updraft at the same level, but an examination of the $Z_{\mathrm{DR}}$ column top (in this case, the level at which $Z_{\mathrm{DR}}$ drops below $1 \mathrm{~dB}$ ) reveals the same result; where the dual-Doppler analyzed updraft is the strongest, drops exhibiting higher $Z_{\mathrm{DR}}$ are lofted higher into the storm. Unfortunately, estimates of the $Z_{\mathrm{DR}}$ column tops with respect to the updraft intensity can, in this case, be misleading. First, incomplete vertical coverage of the WSR$88 \mathrm{D}$ data results in a minimum vertical grid spacing of $500 \mathrm{~m}$. Not only does this make the vertical data distribution sparse, but changes in the $Z_{\mathrm{DR}}$ column top less than $500 \mathrm{~m}$ will not be realized in the analysis. Additionally, vertical velocities obtained from the dualDoppler analysis are known to suffer from large errors, especially at upper levels because of vertically compounding error in an upward-integration method (e.g., Ray et al. 1980; Potvin et al. 2012). The dualDoppler domain in this case extends only to $5 \mathrm{~km}$ AGL, and most of the focus is on updraft intensities at $3.5 \mathrm{~km}$ where Potvin et al. (2012) show errors in vertical velocity to be relatively minimal (RMSE $w \approx$ $3 \mathrm{~m} \mathrm{~s}^{-1}$ at $3.5 \mathrm{~km} \mathrm{AGL)}$.

Despite these problems, it is still possible to substantiate these results without observing the complete evolution of the $Z_{\mathrm{DR}}$ column. Two methods of tracking $Z_{\mathrm{DR}}$ maximum were used to establish further its relationship to the updraft. Initially, both the maximum in vertical velocity and maximum in $Z_{\mathrm{DR}}$ were tracked with time (Fig. 14a), which revealed good agreement with one another early in the period. However, by
2200 UTC, the locations of the updraft and $Z_{\mathrm{DR}}$ maximum became increasingly separated, likely resulting from the presence of large hail. If this were indeed the case, a strengthening updraft would likely correspond with a collapsing center of the $Z_{\mathrm{DR}}$ maximum as large hail, which generally possesses very low $Z_{\mathrm{DR}}$, dominated the radar signal (e.g., Fig. 12; 2159:30 UTC), leaving behind the "ghost" of the $Z_{\mathrm{DR}}$ column as described by Kumjian et al. (2014). Instead of simply tracking the maxima, value-weighted centroids of the updraft and the $Z_{\mathrm{DR}}$ column were calculated and plotted in an attempt to combat the effects of large hail on $Z_{\mathrm{DR}}$ observations. To do this, only vertical velocities greater than $10 \mathrm{~m} \mathrm{~s}^{-1}$ and $Z_{\mathrm{DR}}$ greater than $1 \mathrm{~dB}$ were considered, from which the value-weighted centroid of each quantity was then created for all times (Fig. 14b). This method resulted in substantially better agreement between both variables for all times, including when $Z_{\mathrm{DR}}$ was affected by large hail.

While this case provides additional observations linking $Z_{\mathrm{DR}}$ columns and severe-storm updrafts, it also provides another means of evaluating the performance of the SVAC dual-Doppler analysis technique, in this case through examination of the derived vertical velocity field with respect to unique microphysical characteristics within the storm. Furthermore, the link between the two provides further evidence that the SVAC method can help improve the time resolution of our analyses with reasonable results that could prove to be useful for future multi-Doppler studies. 
a.)
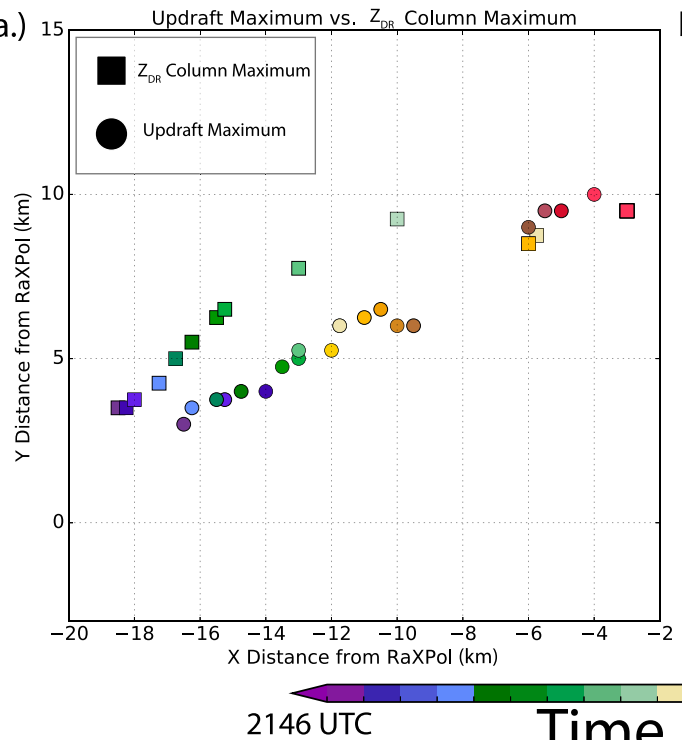

b.)

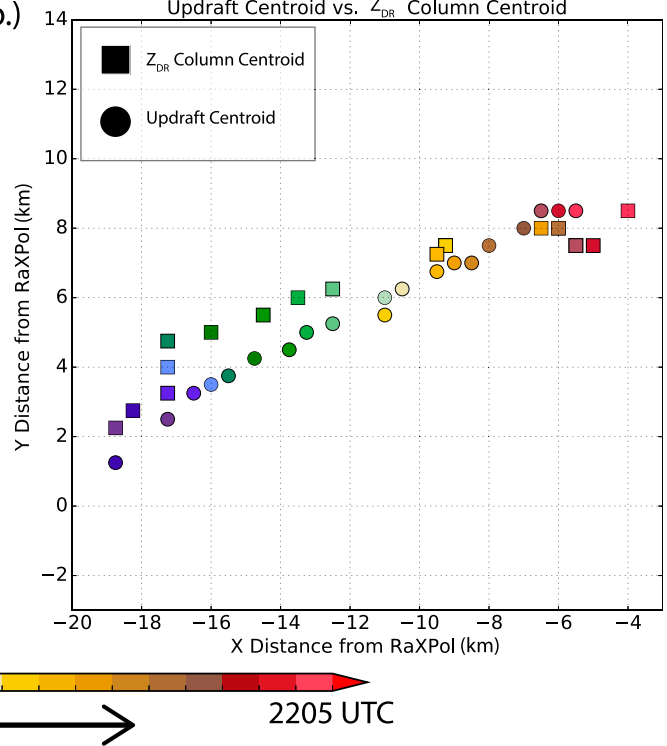

FIG. 14. Tracked locations of the storm updraft $(3.5 \mathrm{~km})$ vs the $Z_{\mathrm{DR}}$ column $(5.5 \mathrm{~km})$ with two separate methods applied to the Edmond-Carney supercell. (a) The first method tracks the maximum in vertical velocity vs the maximum in $Z_{\mathrm{DR}}$ as the storm moves through the domain. (b) The second method masks out velocities less than $10 \mathrm{~m} \mathrm{~s}^{-1}$ and $Z_{\mathrm{DR}}$ less than $1 \mathrm{~dB}$ and calculates the centroid of the object through the domain. The squares $\left(Z_{\mathrm{DR}}\right)$ and the dots $(w)$ are color coordinated based on their time of observation.

\section{b. The Norman-Shawnee and Dodge City tornadoes}

In addition to the Edmond-Carney storm, the SVAC method was also applied to two more tornadic supercells-the 19 May 2013 storm that produced an EF-4 tornado near Shawnee, Oklahoma, and a tornadic supercell near Dodge City, Kansas, on 24 May 2016 (Fig. 2). In both of these cases, limitations in vertical data coverage prevented an identical analysis (particularly for $Z_{\mathrm{DR}}$ columns) to the one presented for the previous case, but relevant results that warrant discussion are presented. These datasets are presented as additional cases in which the SVAC method has been applied in dual-Doppler analyses with encouraging results.

As in Fig. 6, the traditional and SVAC methods were directly compared for both the Norman-Shawnee and Dodge City cases with similar results (Figs. 15 and 16). At worst, the analyses valid at the same time for both methods are nearly identical (with much improved temporal resolution for the SVAC case), and most of the analyses show some differences, including stronger tornado vortices and preservation of the spatial gradients in vorticity.

In the Norman-Shawnee case, the results are similar to those from the aforementioned Edmond-Carney case in all aspects including the maximum temporal resolution achieved by the SVAC method $(\Delta t \approx 50 \mathrm{~s})$.
While the traditional method lacks information on the tornado vortex between scans, the SVAC method's improved temporal resolution shows the decay of the vortex. The primary circulation, which was associated with an EF-4 tornado (labeled "1" in Fig. 15 and 17), weakens below tornado strength through this time, and a second region of rotation forms to its west. This second relative maximum in vertical vorticity (labeled " 2 ") was associated with a funnel cloud, but no tornado was produced (Fig. 17). The suggested cyclic evolution of the tornado and supercell compares well to observations (e.g., Dowell and Bluestein 2002a, b), but the SVAC method is able to capture these shortlived features.

Analyses from the 24 May 2016 Dodge City storm illustrate the low-level evolution of a storm that produced 13 tornadoes over nearly an hour period. Without enhanced temporal resolution, numerous short-lived vortices would fall in between dual-Doppler time steps, missing their existence altogether. For example, between 2329:34 and 2334:27 UTC, the storm began cycling as suggested by two relative vorticity maxima in both the traditional and SVAC analyses (Fig. 17). With time, the new (eastern) vorticity maximum intensified (Fig. 18b), and eventually three tornadoes were all occurring simultaneously (Fig. 18c). While the traditional method does indeed produce the new vorticity 


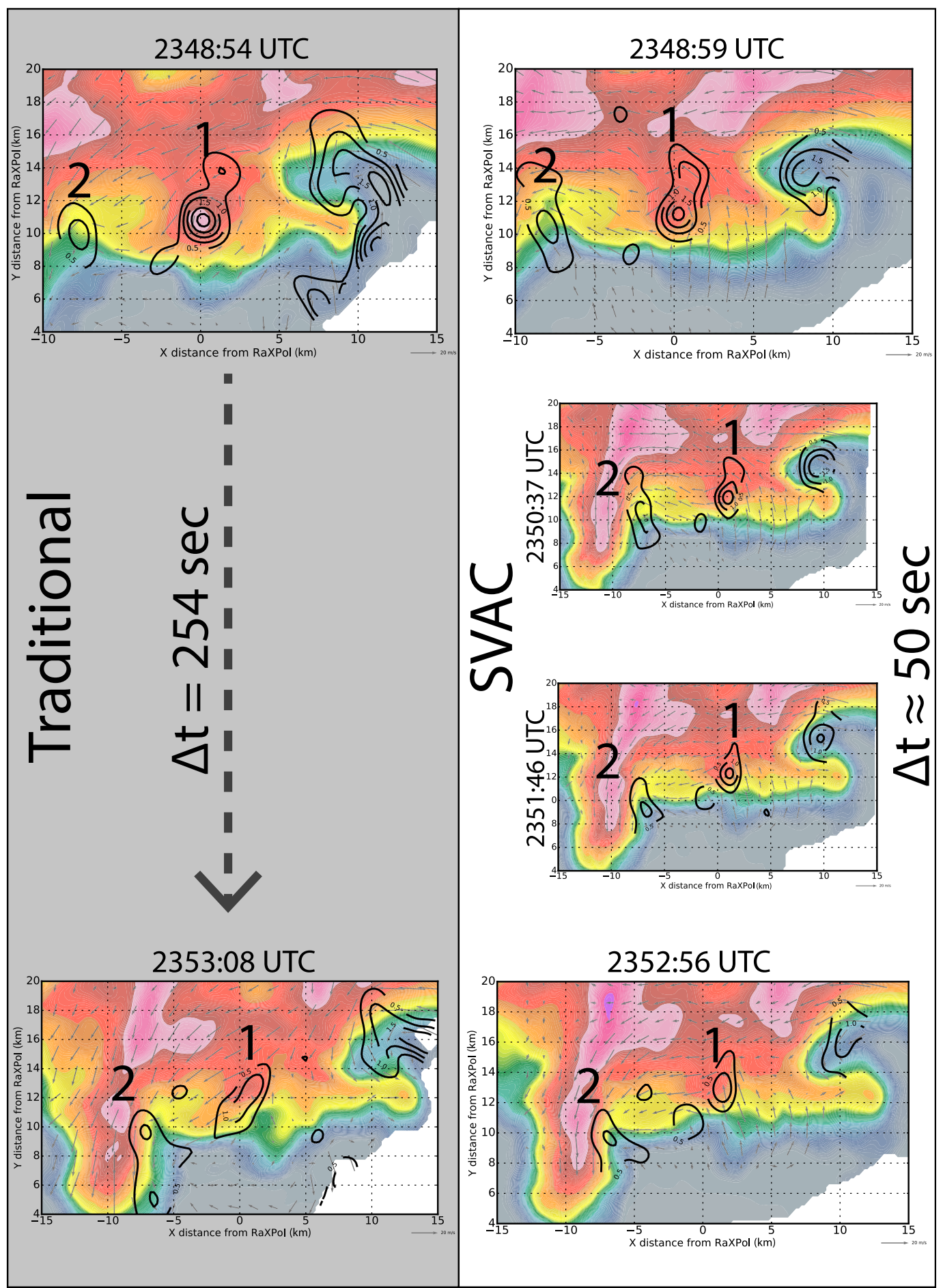

FIG. 15. As in Fig. 6, but for the 19 May 2013 Norman-Shawnee, OK, tornadic supercell. In this case, the WSR88D and corresponding SVAC volumes span from 2348:54 to 2353:08 UTC. The "1" and " 2 " denote the location of two vortices, which correspond to those labeled in Fig. 17. 


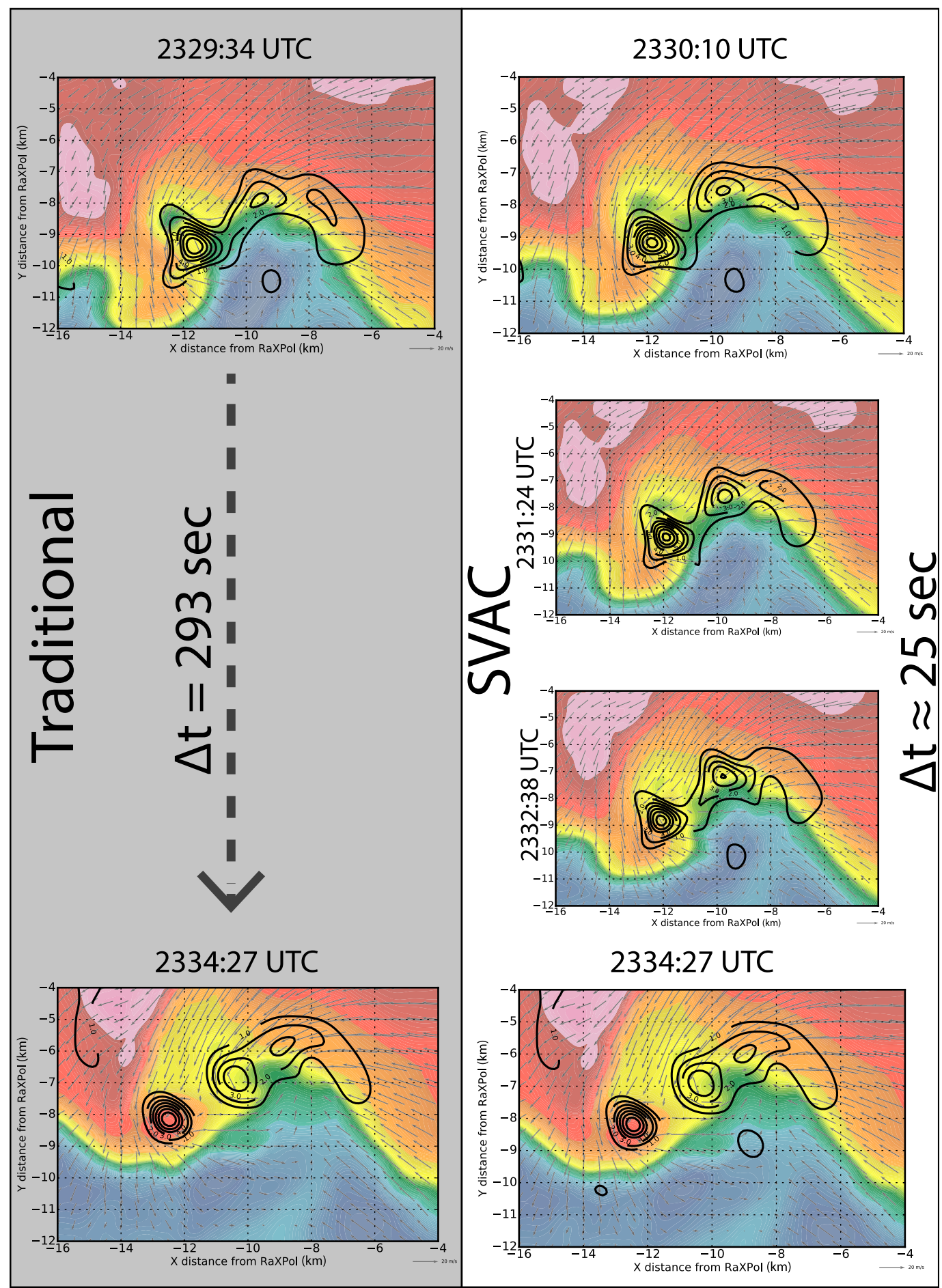

FIG. 16. As in Fig. 6, but for the 24 May 2016 Dodge City, KS, tornadic supercell. In this case, the WSR-88D and corresponding SVAC volumes span from 2329:34 to 2334:27 UTC. In this case, the update time for the SVAC volume is on the order of $25 \mathrm{~s}$, shorter than for either 19 May 2013 case, but at the expense of deep volumetric scans with RaXPol. 


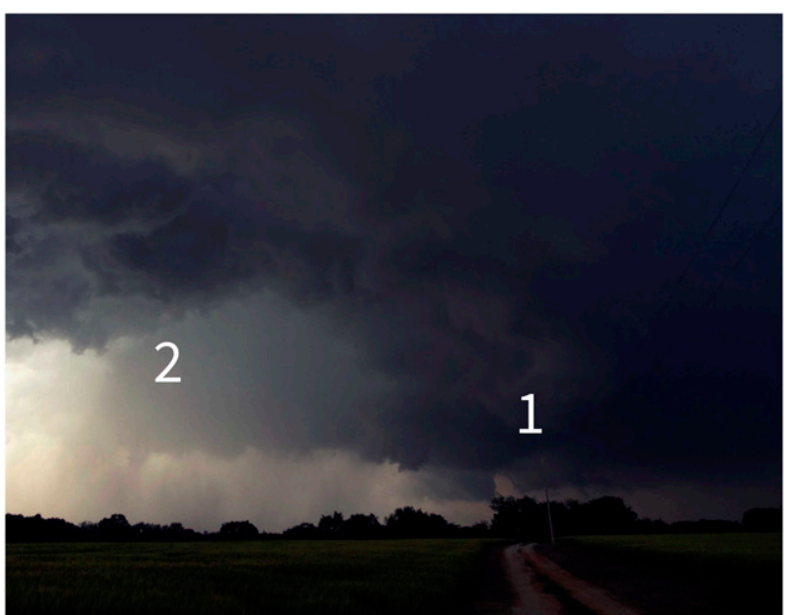

FIG. 17. Photograph looking to the north of the NormanShawnee supercell after the dissipation of the large tornado. The " 1 " denotes the location of the initial, dominant vortex that was associated with the large tornado, and the " 2 " represents a secondary region of rotation that produced a brief funnel cloud but failed to ever produce a tornado. The location of each vortex is also denoted in Fig. 15. (Photograph courtesy of H. Bluestein.)

maximum, it is unable to capture the formation of the secondary vorticity maximum (associated with two needlelike tornadoes) which occurred between volumes. The SVAC method produces the same secondary maximum east of main vortex, but also shows continued intensification maximized at 2332:38 UTC, exactly the time of the two needlelike tornadoes (Fig. 18c).

Both the Norman-Shawnee and Dodge City cases serve as additional datasets from which we can further substantiate the use of this technique and its ability to produce analyses with qualitative veracity. While the results presented on these two cases were brief, the goal was to demonstrate the ability of the SVAC technique to produce reasonable results based on observations (e.g., visual observations, single-Doppler analyses) and findings from previous studies of severe storms. More detailed results of these two cases will be the subject of future papers.

\section{Summary}

The motivation behind this study was to investigate methods of combining two datasets with substantially different temporal resolutions into a three-dimensional dual-Doppler analysis. In general, drastic temporal resolution differences make performing these analyses difficult because of the following reasons: 1 ) the analyses are valid only over a short period of time (in which scans valid at the same time are combined), and 2) benefits of rapid-scanning platforms are rendered effectively useless with respect to dual-Doppler analysis. Three methods of dual-Doppler synthesis were compared to one another to assess the performance of each, mainly focusing on the use of a spatially variable advection correction technique, which allowed for the data to be interpolated to times valid at the same time as individual RaXPol volumes while utilizing a more sophisticated advection scheme. The results of the dual-Doppler analyses revealed that the SVAC method improved on two particular aspects of the analysis: 1) the temporal resolution of the analysis increased nearly fivefold, and 2) the analyses produced results with better precision at all times and heights than did the traditional and hybrid methods.

Technique performance was evaluated through comparisons of the tornado vortex locations from the high-resolution RaXPol radial velocity field with those obtained in each dual-Doppler analysis. While the traditional method had successful results where the volumes were synchronized, the SVAC method resulted in vortex locations with the smallest horizontal displacement and smallest standard deviation overall. In addition, the $Z_{\mathrm{DR}}$ column data were used for comparison with the midlevel updraft, mainly as an evaluation of the SVAC method's ability to produce reasonable spatial characteristics of the updraft (e.g., location, size, and shape). The Norman-Shawnee and Dodge City cases both provided additional analyses in which results were obtained consistent with the general storm evolution, including evidence of cyclic tornadogenesis and brief events of multiple tornadoes. While errors associated with dual-Doppler retrievals of the vertical wind field undoubtedly remain regardless of analysis technique, results using the SVAC method lend confidence in our ability to produce qualitatively and quantitatively reasonable results.

Future work aimed at understanding the limitations of the SVAC technique is vital, especially at higher resolution where small-scale changes are less effected by smoothing constraints leading to larger impacts on the analyses (i.e., how the SVAC technique will handle the evolution of finer-scale, shorter-lived features in the dual-Doppler analysis). Future OSSE experiments are also possible, which would allow for more rigorous quantitative tests through utilization of the numerical model as a control. As radar technology continues to evolve, rapid-scanning radars are becoming more common. Implementation of the SVAC technique could provide us the ability to use these high-temporal observations with slower scanning instruments to provide more rapid-multi-Doppler analyses well into the future. 

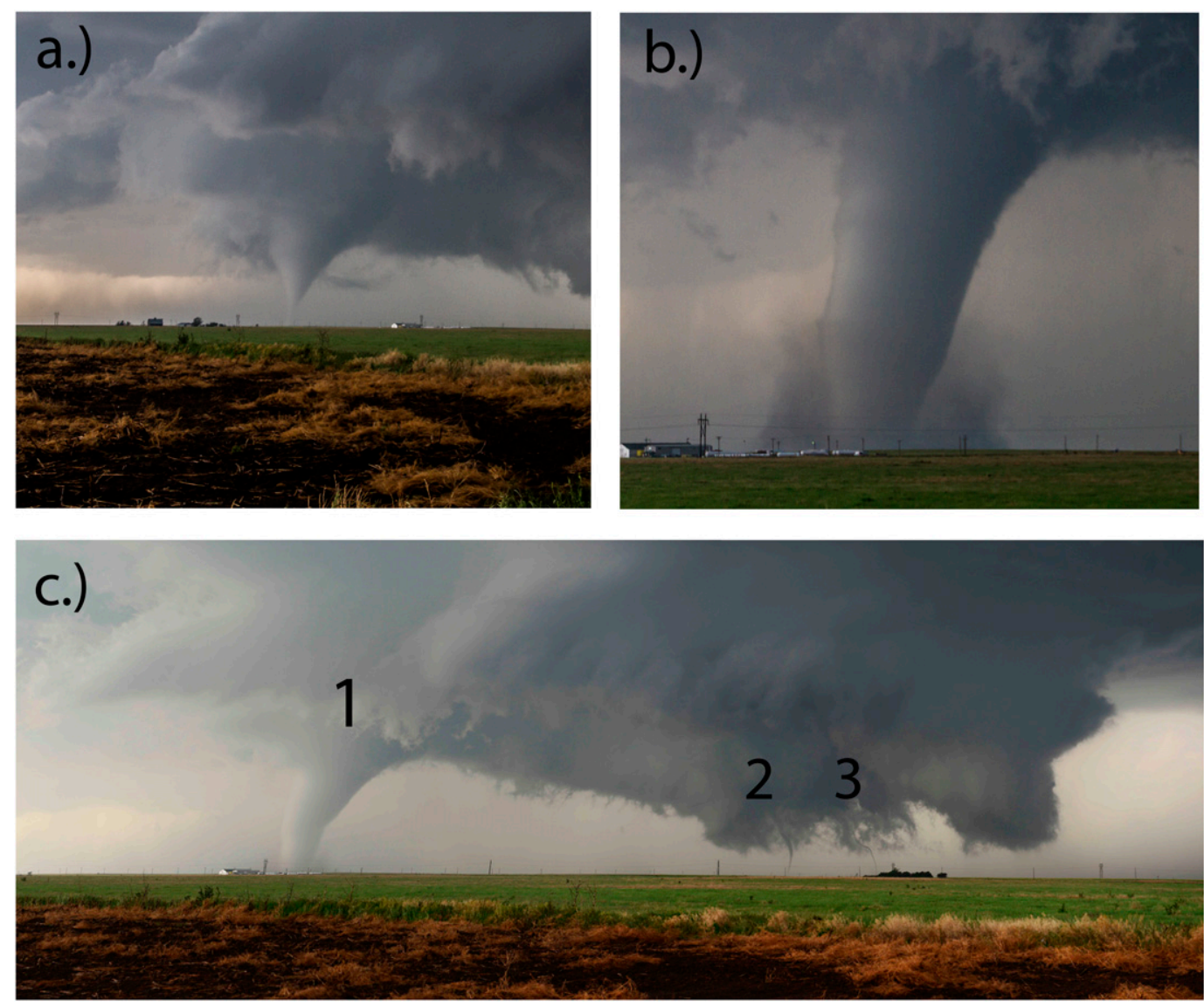

FIG. 18. Select photos corresponding to the dual-Doppler analyses times (Fig. 17) near Dodge City during RaXPol observation of eight tornadoes. At approximately (a) 2328 UTC the new mesocyclone produces a tornado, which would persist through the end of the deployment. That same tornado became stronger and larger by (b) 2332 UTC, and by (c) 2332:38 UTC produced a second ("2") and third ("3") tornado, both needlelike and transient in nature, formed coincident with a new mesocyclone. In each case, dual-Doppler analyses captured the cyclic tornadogenesis events as a total of 13 tornadoes in all were produced. [Photos in (a) and (b) were taken by the first author; photo in (c) courtesy of H. Bluestein.]

Acknowledgments. This work was funded under NSF Grants AGS-1262048 and AGS-1560945. One of the authors (A. S.) acknowledges support by the National Science Foundation under Grant AGS-135698. The authors are grateful for John Meier, Boon Leng Cheong, and the Advanced Radar Research Center at OU for housing and maintaining RaXPol. We thank Roger Wakimoto and Kyle Thiem for numerous discussions regarding the first author's work at the University of Oklahoma.

\section{REFERENCES}

Alexander, C. R., and J. Wurman, 2005: The 30 May 1998 Spencer, South Dakota, storm. Part I: The structural evolution and environment of the tornadoes. Mon. Wea. Rev., 133, 72-97, https://doi.org/10.1175/MWR-2855.1.
Atkins, N. T., A. McGee, R. Ducharme, R. M. Wakimoto, and J. Wurman, 2012: The LaGrange tornado during VORTEX2. Part II: Photogrammetric analysis of the tornado combined with dual-Doppler radar data. Mon. Wea. Rev., 140, 2939-2958, https://doi.org/10.1175/MWR-D-11-00285.1.

Atlas, D., R. Srivastava, and R. S. Sekhon, 1973: Doppler radar characteristics of precipitation at vertical incidence. Rev. Geophys., 11, 1-35, https://doi.org/10.1029/RG011i001p00001.

Barnes, S. L., 1964: A technique for maximizing details in numerical weather map analysis. J. Appl. Meteor., 3, 396-409, https://doi.org/10.1175/1520-0450(1964) $003<0396$ :ATFMDI $>2.0 . \mathrm{CO} ; 2$.

Bell, M. M., W. Lee, C. A. Wolff, and H. Cai, 2013: A Solo-based automated quality control algorithm for airborne tail Doppler radar data. J. Appl. Meteor. Climatol., 52, 2509-2528, https:// doi.org/10.1175/JAMC-D-12-0283.1.

Biggerstaff, M. I., and Coauthors, 2005: The Shared Mobile Atmospheric Research and Teaching radar: A collaboration to enhance research and teaching. Bull. Amer. Meteor. Soc., 86, 1263-1274, https://doi.org/10.1175/BAMS-86-9-1263. 
Bluestein, H. B., and A. L. Pazmany, 2000: Observations of tornadoes and other convective phenomena with a mobile, $3-\mathrm{mm}$ wavelength, Doppler radar: The spring 1999 field experiment. Bull. Amer. Meteor. Soc., 81, 2939-2951, https://doi.org/ 10.1175/1520-0477(2000)081<2939:OOTAOC >2.3.CO;2.

,-- J. C. Galloway, and R. E. McIntosh, 1995: Studies of the substructure of severe convective storms using a mobile 3-mmwavelength Doppler radar. Bull. Amer. Meteor. Soc., 76, 2155-2169, https://doi.org/10.1175/1520-0477(1995)076<2155: SOTSOS $>2.0 . \mathrm{CO} ; 2$.

- M. M. French, R. L. Tanamachi, S. Frasier, K. Hardwick, F. Junyent, and A. L. Pazmany, 2007: Close-range observations of tornadoes in supercells made with a dual-polarization, X-band, mobile Doppler radar. Mon. Wea. Rev., 135, 1522-1543, https://doi.org/10.1175/MWR3349.1.

,-- I. PopStefanija, R. T. Bluth, and J. B. Knorr, 2010: A mobile, phased-array Doppler radar for the study of severe convective storms. Bull. Amer. Meteor. Soc., 91, 579-600, https://doi.org/10.1175/2009BAMS2914.1.

_ J. C. Snyder, and J. B. Houser, 2015: A multi-scale overview of the El Reno, Oklahoma, tornadic supercell of 31 May 2013. Wea. Forecasting, 30, 525-552, https://doi.org/10.1175/WAFD-14-00152.1.

_ Z Z. B. Wienhoff, D. D. Turner, D. W. Reif, J. C. Snyder, K. J. Thiem, and J. B. Houser, 2017: A comparison of the finescale structures of a prefrontal wind-shift line and a strong cold front in the Southern Plains of the United States. Mon. Wea. Rev., 145, 3307-3330, https://doi.org/10.1175/MWR-D16-0403.1.

Brandes, E. A., 1977a: Flow in severe thunderstorms observed by dualDoppler radar. Mon. Wea. Rev., 105, 113-120, https://doi.org/ 10.1175/1520-0493(1977)105<0113:FISTOB > 2.0.CO;2.

_ 1977b: Gust front evolution and tornado genesis as viewed by Doppler radar. J. Appl. Meteor., 16, 333-338, https://doi.org/ 10.1175/1520-0450(1977)016<0333:GFEATG >2.0.CO;2.

_ 1978: Mesocyclone evolution and tornadogenesis: Some observations. Mon. Wea. Rev., 106, 995-1011, https://doi.org/ 10.1175/1520-0493(1978)106<0995:MEATSO > 2.0.CO;2.

_ 1984a: Relationships between radar-derived thermodynamic variables and tornadogenesis. Mon. Wea. Rev., 112, 1033-1052, https://doi.org/10.1175/1520-0493(1984)112<1033: RBRDTV $>2.0 . C O ; 2$

_ 1984b: Vertical vorticity generation and mesocyclone sustenance in tornadic thunderstorms: The observational evidence. Mon. Wea. Rev., 112, 2253-2269, https://doi.org/10.1175/15200493(1984)112<2253:VVGAMS >2.0.CO;2.

Bringi, V. N., D. A. Burrows, and S. M. Menon, 1991: Multiparameter radar and aircraft study of raindrop spectral evolution in warmbased clouds. J. Appl. Meteor., 30, 853-880, https://doi.org/ 10.1175/1520-0450(1991)030<0853:MRAASO > 2.0.CO;2.

_, K. Knupp, A. Detwiler, L. Liu, I. J. Caylor, and R. A. Black, 1997: Evolution of a Florida thunderstorm during the Convection and Precipitation/Electrification Experiment: The case of 9 August 1991. Mon. Wea. Rev., 125, 2131-2160, https://doi.org/ 10.1175/1520-0493(1997)125<2131:EOAFTD>2.0.CO;2.

Brown, R. A., and R. L. Peace Jr., 1968: Mesoanalysis of convective storms utilizing observations from two Doppler radars. Preprints, 13th Radar Meteor. Conf., Montreal, QC, Canada, Amer. Meteor. Soc., 188-191.

, D. W. Burgess, J. K. Carter, L. R. Lemon, and D. Sirmans, 1975: NSSL dual-Doppler radar measurements in tornadic storms: A preview. Bull. Amer. Meteor. Soc., 56, 524-526, https://doi.org/ 10.1175/1520-0477(1975)056<0524:NDDRMI>2.0.CO;2.
Chong, M., J. Testud, and F. Roux, 1983: Three-dimensional wind field analysis from dual-Doppler radar data. Part II: Minimizing the error due to temporal variation. J. Climate Appl. Meteor., 22, 1216-1226, https://doi.org/10.1175/ 1520-0450(1983)022<1216:TDWFAF $>2.0$.CO;2.

Conway, J. W., and D. S. Zrnić, 1993: A study of embryo production and hail growth using dual-Doppler and multiparameter radars. Mon. Wea. Rev., 121, 2511-2528, https://doi.org/10.1175/ 1520-0493(1993)121<2511:ASOEPA>2.0.CO;2.

Crowe, C. C., W. A. Petersen, and L. D. Carey, 2009: A dualpolarization investigation of tornado warned cells associated with Hurricane Rita (2005). 34th Conf. on Radar Meteorology, Williamsburg, VA, Amer. Meteor. Soc., P13.7, https://ams.confex.com/ams/pdfpapers/155314.pdf.

Dowell, D. C., and H. B. Bluestein, 1997: The Arcadia, Oklahoma, storm of 17 May 1981: Analysis of a supercell during tornadogenesis. Mon. Wea. Rev., 125, 2562-2582, https://doi.org/ 10.1175/1520-0493(1997)125<2562:TAOSOM >2.0.CO;2.

— and _ 2002a: The 8 June 1995 McLean, Texas, storm. Part I: Observations of cyclic tornadogenesis. Mon. Wea. Rev., 130, 2626-2648, https://doi.org/10.1175/1520-0493(2002)130<2626: TJMTSP $>2.0 . \mathrm{CO} ; 2$.

— and - 2002b: The 8 June 1995 McLean, Texas, storm. Part II: Cyclic tornado formation, maintenance, and dissipation. Mon. Wea. Rev., 130, 2649-2670, https://doi.org/10.1175/ 1520-0493(2002)130<2649:TJMTSP > 2.0.CO;2.

Eagleman, J. R., and W. C. Lin, 1977: Severe thunderstorm internal structure from dual-Doppler radar measurements. J. Appl. Meteor., 16, 1036-1048, https://doi.org/10.1175/1520-0450-16.10.1036.

Fujita, T. T., D. L. Bradbury, and C. F. Van Thullenar, 1970: Palm Sunday tornadoes of April 1, 1965. Mon. Wea. Rev., 98, 29-69, https://doi.org/10.1175/1520-0493(1970) $098<0029:$ PSTOA $>2.3 . \mathrm{CO} ; 2$.

Germann, U., and I. Zawadzki, 2002: Scale-dependence of the predictability of precipitation from continental radar images. Part I: Description of the methodology. Mon. Wea. Rev., 130, 2859-2873, https://doi.org/10.1175/1520-0493(2002)130<2859: $\mathrm{SDOTPO}>2.0 . \mathrm{CO} ; 2$.

Houser, J. B., 2013: Observations of supercell tornado evolution using a mobile, rapid-scan, X-band radar. Ph.D. thesis, University of Oklahoma, Norman, OK, $282 \mathrm{pp}$.

Houser, J. L., H. B. Bluestein, and J. C. Snyder, 2015: Rapid-scan, polarimetric, Doppler radar observations of tornadogenesis and tornado dissipation in a tornadic supercell: The "El Reno, Oklahoma" storm of 24 May 2011. Mon. Wea. Rev., 143, 2685-2710, https://doi.org/10.1175/MWR-D-14-00253.1.

- _ - and J. Snyder, 2016: A finescale radar examination of the tornadic debris signature and weak-echo reflectivity band associated with a large, violent tornado. Mon. Wea. Rev., 144, 4101-4130, https://doi.org/10.1175/MWR-D-15-0408.1.

Hubbert, J. C., V. N. Bringi, L. D. Carey, and S. Bolen, 1998: CSUCHILL polarimetric radar measurements from a severe hail storm in eastern Colorado. J. Appl. Meteor., 37, 749-775, https://doi.org/10.1175/1520-0450(1998)037<0749:CCPRMF $>2.0$. $\mathrm{CO} ; 2$.

Illingworth, A. J., J. W. F. Goddard, and S. M. Cherry, 1987: Polarization radar studies of precipitation development in convective storms. Quart. J. Roy. Meteor. Soc., 113, 469-489, https://doi.org/10.1002/qj.49711347604.

Kennedy, P. C., S. A. Rutledge, W. A. Petersen, and V. N. Bringi, 2001: Polarimetric radar observations of hail formation. J. Appl. Meteor., 40, 1347-1366, https://doi.org/10.1175/ 1520-0450(2001)040<1347:PROOHF>2.0.CO;2. 
Knupp, K. R., and Coauthors, 2014: Meteorological overview of the devastating 27 April 2011 tornado outbreak. Bull. Amer. Meteor. Soc., 95, 1041-1062, https://doi.org/10.1175/BAMS-D11-00229.1.

Koch, S. E., M. Desjardins, and P. J. Kocin, 1983: An interactive Barnes objective map analysis scheme for use with satellite and conventional data. J. Climate Appl. Meteor., 22, 1487-1503, https://doi.org/10.1175/1520-0450(1983)022<1487: AIBOMA $>2.0 . \mathrm{CO} ; 2$.

Kosiba, K., J. Wurman, Y. Richardson, P. Markowski, P. Robinson, and J. Marquis, 2013: Genesis of the Goshen County, Wyoming, tornado on 5 June 2009 during VORTEX2. Mon. Wea. Rev., 141, 1157-1181, https://doi.org/10.1175/MWR-D12-00056.1.

Kramar, M. R., H. B. Bluestein, A. L. Pazmany, and J. D. Tuttle, 2005: The "Owl Horn" radar signature in developing Southern Plains supercells. Mon. Wea. Rev., 133, 2608-2634, https:// doi.org/10.1175/MWR2992.1.

Kumjian, M. R., and A. V. Ryzhkov, 2008: Polarimetric signatures in supercell thunderstorms. J. Appl. Meteor. Climatol., 47, 1940-1961, https://doi.org/10.1175/2007JAMC1874.1.

— A. P. Khain, N. Benmoshe, E. Ilotoviz, A. V. Ryzhkov, and V. T. Phillips, 2014: The anatomy and physics of ZDR columns: Investigating a polarimetric radar signature with a spectral bin microphysical model. J. Appl. Meteor. Climatol., 53, 1820-1843, https://doi.org/10.1175/JAMC-D-13-0354.1.

Laroche, S., and I. Zawadzki, 1994: A variational analysis method for retrieval of three-dimensional wind field from single-Doppler radar data. J. Atmos. Sci., 51, 2664-2682, https://doi.org/10.1175/ 1520-0469(1994)051<2664:AVAMFR>2.0.CO;2.

Liou, Y.-C., 2002: An explanation of the wind speed underestimation obtained from a least squares type single-Doppler radar velocity retrieval method. J. Appl. Meteor., 41, 811-823, https://doi.org/ 10.1175/1520-0450(2002)041<0811:AEOTWS >2.0.CO;2.

Loney, M. L., D. S. Zrnić, J. M. Straka, and A. V. Ryzhkov, 2002: Enhanced polarimetric radar signatures above the melting level in a supercell storm. J. Appl. Meteor., 41, 1179-1194, https://doi.org/ 10.1175/1520-0450(2002)041<1179:EPRSAT>2.0.CO;2.

Mahale, V. N., J. A. Brotzge, and H. B. Bluestein, 2012: An analysis of vortices embedded within a quasi-linear convective system using X-band polarimetric radar. Wea. Forecasting, 27, 1520-1537, https://doi.org/10.1175/WAF-D-11-00135.1.

Majcen, M., P. Markowski, Y. Richardson, D. Dowell, and J. Wurman, 2008: Multipass objective analyses of Doppler radar data. J. Atmos. Oceanic Technol., 25, 1845-1858, https:// doi.org/10.1175/2008JTECHA1089.1.

Markowski, P., and Coauthors, 2012a: The pretornadic phase of the Goshen County, Wyoming, supercell of 5 June 2009 intercepted by VORTEX2. Part I: Evolution of kinematic and surface thermodynamic fields. Mon. Wea. Rev., 140, 2887-2915, https://doi.org/10.1175/MWR-D-11-00336.1.

_ , and Coauthors, 2012b: The pretornadic phase of the Goshen County, Wyoming, supercell of 5 June 2009 intercepted by VORTEX2. Part II: Intensification of low-level rotation. Mon. Wea. Rev., 140, 2916-2938, https://doi.org/10.1175/MWR-D11-00337.1.

Marquis, J., Y. Richardson, J. Wurman, and P. Markowski, 2008: Single- and dual-Doppler analysis of a tornadic vortex and surrounding storm-scale flow in the Crowell, Texas, supercell of 30 April 2000. Mon. Wea. Rev., 136, 5017-5043, https://doi.org/ 10.1175/2008MWR2442.1.

Palmer, R., and Coauthors, 2009: Weather radar education at the University of Oklahoma-An integrated interdisciplinary approach. Bull. Amer. Meteor. Soc., 90, 1277-1282, https://doi. org/10.1175/2009BAMS2738.1.

Pauley, P. M., and X. Wu, 1990: The theoretical, discrete, and actual response of the Barnes objective analysis scheme for one-and twodimensional fields. Mon. Wea. Rev., 118, 1145-1164, https://doi. org/10.1175/1520-0493(1990)118<1145:TTDAAR > 2.0.CO;2.

Pazmany, A. L., J. B. Mead, H. B. Bluestein, J. C. Snyder, and J. B. Houser, 2013: A mobile rapid-scanning X-band polarimetric (RaXPol) Doppler radar system. J. Atmos. Oceanic Technol., 30, 1398-1413, https://doi.org/10.1175/JTECH-D-12-00166.1.

Potvin, C. K., L. J. Wicker, and A. Shapiro, 2012: Assessing errors in variational dual-Doppler wind syntheses of supercell thunderstorms observed by storm-scale mobile radars. J. Atmos. Oceanic Technol., 29, 1009-1025, https:// doi.org/10.1175/JTECH-D-11-00177.1.

Ray, P. S., 1976: Vorticity and divergence fields within tornadic storms from dual- Doppler observations. J. Appl. Meteor., 15, 879-890, https://doi.org/10.1175/1520-0450 (1976)015<0879:VADFWT>2.0.CO;2.

, R. Doviak, G. Walker, D. Sirmans, J. Carter, and B. Bumgarner, 1975: Dual-Doppler observation of a tornadic storm. J. Appl. Meteor., 14, 1521-1530, https://doi.org/ 10.1175/1520-0450(1975)014<1521:DDOOAT>2.0.CO;2.

— C. L. Ziegler, W. Bumgarner, and R. J. Serafin, 1980: Singleand multiple-Doppler radar observations of tornadic storms. Mon. Wea. Rev., 108, 1607-1625, https://doi.org/10.1175/15200493(1980)108<1607:SAMDRO > 2.0.CO;2.

- - B. Johnson, K. Johnson, J. Bradberry, J. Stephens, K. Wagner, R. Wilhelmson, and J. Klemp, 1981: The morphology of several tornadic storms on 20 May 1977. J. Atmos. Sci., 38, 1643-1663, https://doi.org/10.1175/ 1520-0469(1981)038<1643:TMOSTS > 2.0.CO;2.

Scharfenberg, K., P. Schlatter, D. Miller, and C. A. Whittier, 2004: The use of the " $Z_{D R}$ column" signature in short-term thunderstorm forecasts. 11th Conf. on Aviation, Range, and Aerospace Meteorology, Hyannis, MA, Amer. Meteor. Soc., P5.5., https://ams.confex.com/ams/pdfpapers/81805.pdf.

Schroth, A. C., M. S. Chandra, and P. F. Mesichner, 1988: A C-Band coherent polarimetric radar for propagation and cloud physics research. J. Atmos. Oceanic Technol., 5, 803-822, https://doi.org/ 10.1175/1520-0426(1988)005<0803:ABCPRF>2.0.CO;2.

Shapiro, A., K. M. Willingham, and C. K. Potvin, 2010a: Spatially variable advection correction of radar data. Part I: Theoretical considerations. J. Atmos. Sci., 67, 3445-3456, https://doi.org/ 10.1175/2010JAS3465.1.

,$- \ldots$, and _- 2010b: Spatially variable advection correction of radar data. Part II: Test results. J. Atmos. Sci., 67, 3457-3470, https://doi.org/10.1175/2010JAS3466.1.

Snyder, J. C., and H. B. Bluestein, 2014: Some considerations for the use of mobile Doppler radar data for tornado intensity determination. Wea. Forecasting, 29, 799-827, https://doi.org/ 10.1175/WAF-D-14-00026.1.

,,-- V. Venkatesh, and S. J. Frasier, 2013: Observations of polarimetric signatures in supercells by an X-band mobile Doppler radar. Mon. Wea. Rev., 141, 3-29, https://doi.org/ 10.1175/MWR-D-12-00068.1.

— A. V. Ryzhkov, M. R. Kumjian, A. P. Khain, and J. Picca, 2015: A $Z_{\mathrm{DR}}$ column detection algorithm to examine convective storm updrafts. Wea. Forecasting, 30, 1819-1844, https://doi.org/10.1175/WAF-D-15-0068.1.

— H. B. Bluestein, D. T. Dawson II, and Y. Jung, 2017: Simulations of polarimetric, X-band radar signatures in supercells. Part I: Description of experiment and simulated $\rho_{\mathrm{hv}}$ rings. 
J. Appl. Meteor. Climatol., 56, 1977-1999, https://doi.org/ 10.1175/JAMC-D-16-0138.1.

Tanamachi, R. L., and P. L. Heinselman, 2016: Rapid-scan, polarimetric observations of central Oklahoma severe storms on 31 May 2013. Wea. Forecasting, 31, 19-42, https://doi.org/ 10.1175/WAF-D-15-0111.1.

- H. B. Bluestein, J. B. Houser, S. J. Frasier, and K. M. Hardwick, 2012: Mobile, X-band, polarimetric Doppler radar observations of the 4 May 2007 Greensburg, Kansas, tornadic supercell. Mon. Wea. Rev., 140, 2103-2125, https://doi.org/ 10.1175/MWR-D-11-00142.1.

Torres, S., and C. D. Curtis, 2006: Design considerations for improved tornado detection using super-resolution data on the NEXRAD network. Preprints, Fourth European Conf. on Radar Meteorology and Hydrology (ERAD), Barcelona, Spain, ERAD, 92-95.

Wakimoto, R. M., N. T. Atkins, and J. Wurman, 2011: The LaGrange tornado during VORTEX2. Part I: Photogrammetric analysis of the tornado combined with single-Doppler radar data. Mon. Wea. Rev., 139, 2233-2258, https://doi.org/10.1175/ 2010MWR3568.1.

- P. Stauffer, W.-C. Lee, N. T. Atkins, and J. Wurman, 2012: Finescale structure of the LaGrange, Wyoming, tornado during VORTEX2: GBVTD and photogrammetric analyses. Mon. Wea. Rev., 140, 3397-3418, https://doi.org/10.1175/ MWR-D-12-00036.1.
K. M. Butler, H. B. Bluestein, K. Thiem, J. Snyder, and J. Houser, 2015: Photogrammetric analysis of the $2013 \mathrm{El}$ Reno tornado combined with mobile X-Band polarimetric radar data. Mon. Wea. Rev., 143, 2657-2683, https://doi.org/ 10.1175/MWR-D-15-0034.1.

_ - and Coauthors, 2016: Aerial damage survey of the 2013 El Reno tornado combined with mobile radar data. Mon. Wea. Rev., 144, 1749-1776, https://doi.org/10.1175/MWR-D-15-0367.1.

Wurman, J., J. Straka, E. Rasmussen, M. Randall, and A. Zahrai, 1997: Design and deployment of a portable, pencil-beam, pulsed, 3-cm Doppler radar. J. Atmos. Oceanic Technol., 14, 1502-1512, https://doi.org/10.1175/1520-0426(1997)014<1502: DADOAP $>2.0 . \mathrm{CO} ; 2$.

—, Y. Richardson, C. Alexander, S. Weygandt, and P. F. Zhang, 2007a: Dual-Doppler analysis of winds and vorticity budget terms near a tornado. Mon. Wea. Rev., 135, 2392-2405, https:// doi.org/10.1175/MWR3404.1.

,,,$--- \ldots$, and,$- 2007 \mathrm{~b}$ : Dual-Doppler and singleDoppler analysis of a tornadic storm undergoing mergers and repeated tornadogenesis. Mon. Wea. Rev., 135, 736-758, https://doi.org/10.1175/MWR3276.1.

, K. Kosiba, P. Markowski, Y. Richardson, D. Dowell, and P. Robinson, 2010: Finescale single-and dual-Doppler analysis of tornado intensification, maintenance, and dissipation in the Orleans, Nebraska, supercell. Mon. Wea. Rev., 138, 4439-4455, https://doi.org/10.1175/2010MWR3330.1. 